\title{
The Modification of Bottom Boundary Layer Turbulence and Mixing by Internal Waves Shoaling on a Barrier Reef
}

\author{
KRISTEN A. DAVIS \\ Environmental Fluid Mechanics Laboratory, Stanford University, Stanford, California, and Physical Oceanography, \\ Woods Hole Oceanographic Institution, Woods Hole, Massachusetts \\ STEPHEN G. MONISMITH \\ Environmental Fluid Mechanics Laboratory, Stanford University, Stanford, California
}

(Manuscript received 21 August 2009, in final form 12 March 2011)

\begin{abstract}
Results are presented from an observational study of stratified, turbulent flow in the bottom boundary layer on the outer southeast Florida shelf. Measurements of momentum and heat fluxes were made using an array of acoustic Doppler velocimeters and fast-response temperature sensors in the bottom $3 \mathrm{~m}$ over a rough reef slope. Direct estimates of flux Richardson number $R_{f}$ confirm previous laboratory, numerical, and observational work, which find mixing efficiency not to be a constant but rather to vary with $\mathrm{Fr}_{t}, \mathrm{Re}_{b}$, and $\mathrm{Ri}_{g}$. These results depart from previous observations in that the highest levels of mixing efficiency occur for $\operatorname{Fr}_{t}<1$, suggesting that efficient mixing can also happen in regions of buoyancy-controlled turbulence. Generally, the authors find that turbulence in the reef bottom boundary layer is highly variable in time and modified by nearbed flow, shear, and stratification driven by shoaling internal waves.
\end{abstract}

\section{Introduction}

Coastal seas play an important role in mixing the oceans (Munk and Wunsch 1998). Much of what we know about turbulent mixing on the continental shelf is derived from microstructure profiler measurements (Lueck et al. 2002). Microstructure observations have provided crucial insight into the science of ocean turbulence, but they also reveal the inhomogeneous and unsteady nature of the velocity and density fields in the coastal ocean and thus the difficulty of characterizing small-scale turbulent mixing in the ocean with spatially and temporally discrete measurements (Ivey et al. 2008; Moum and Rippeth 2008). Observations of turbulence from moored instrumentation on the continental shelf are less common because of the difficulty of collecting high-frequency data in remote locations, but examples include measurements of velocity and sound speed in the New England shelf bottom boundary layer using a bottom-mounted tripod by Shaw et al. (2001), bottom boundary layer measurements

Corresponding author address: Kristen A. Davis, Applied Physics Laboratory, University of Washington, Seattle, WA 98105.

E-mail:kadavis@uw.edu over the Oregon shelf by Perlin et al. (2005a), and turbulence measurements over a sandy coastal bed using submersible particle image velocimetry (PIV) systems by Doron et al. (2001) and Smith et al. (2002).

Turbulence dynamics can be represented by the turbulent kinetic energy (TKE) equation,

$$
\begin{aligned}
- & \frac{\partial}{\partial t}\left(\overline{\frac{u_{i}^{\prime} u_{i}^{\prime}}{2}}\right)-U_{j} \frac{\partial}{\partial x_{j}}\left(\overline{\frac{u_{i}^{\prime} u_{i}^{\prime}}{2}}\right) \\
& -\frac{\partial}{\partial x_{j}}\left(\frac{1}{\rho_{0}} \overline{u_{j}^{\prime} p^{\prime}}+\frac{1}{2} \overline{u_{j}^{\prime} u_{i}^{\prime} u_{i}^{\prime}}-2 \nu \overline{u_{i}^{\prime} e_{i j}}\right) \\
& -\overline{u_{i}^{\prime} u_{j}^{\prime}} \frac{\partial U_{i}}{\partial x_{j}}-\overline{\tilde{r}_{i j} \frac{\partial \tilde{u}_{i}}{\partial x_{j}}}-\overline{\tilde{u}_{j} \frac{\partial}{\partial x_{j}}\left(\frac{1}{2} \tilde{r}_{i i}\right)}=\frac{g}{\rho_{0}} \overline{u_{3}^{\prime} \rho^{\prime}}+\varepsilon,
\end{aligned}
$$

where $t$ is time; $x_{j}=[x, y, z]$ represents the threedimensional spatial coordinate axes, with $z$ positive upward; $u_{i}=[u, v, w]$ is the velocity vector; $\rho$ is density; $p$ is pressure; $g$ is gravitational acceleration; $\nu$ is kinematic viscosity; $e_{i j}=(1 / 2)\left[\left(\partial u_{i} / \partial x_{j}\right)+\left(\partial u_{j} / \partial x_{i}\right)\right]$ is the strain rate tensor; and $\varepsilon$ is the rate of turbulent kinetic energy 
dissipation. The velocity and density fields are decomposed into three parts,

$$
\begin{gathered}
u_{i}=U_{i}+\tilde{u}_{i}+u_{i}^{\prime} \\
\rho=\rho_{0}+\tilde{\rho}+\rho^{\prime},
\end{gathered}
$$

a time-averaged value (capital letter or subscript 0 ), a periodic component (tilde), and a fluctuating or turbulent component (prime). Overbars represent Reynolds averaging. The first and second terms on the left-hand side of Eq. (1) represent the rate of change of TKE and the advection of TKE, respectively. The third and fourth terms represent the spatial transport of turbulence by pressure and turbulence fluctuations, respectively, and the fifth term is viscous transport. The sixth term on the left-hand side is the shear production of turbulence $P$. The last two terms on the left-hand side represent waveturbulence interactions and only appear in a triple decomposition of the TKE equation, as done in Reynolds and Hussain (1972), where $\tilde{r}_{i j}=\left\langle u_{i}^{\prime} u_{j}^{\prime}\right\rangle-\overline{u_{i}^{\prime} u_{j}^{\prime}}$ and \langle\rangle represent wave-phase averaging. On the right-hand side of Eq. (1), the first term represents turbulent buoyancy flux $B$ and the last represents viscous dissipation.

In a steady, horizontally homogenous boundary layer flow, it is often assumed that the advection, transport, and buoyancy terms of Eq. (1) are negligible compared to the production and dissipation terms and thus there is a local equilibrium between $P$ and $\varepsilon$. Further, it is thought that, near the bed, the velocity distribution follows the law of the wall and is a function of a characteristic roughness length $z_{0}$ and the friction velocity $u_{*}=\sqrt{\tau_{0} / \rho}$, where $\tau_{0}$ is shear stress at the bed. Field measurements of currents in well-mixed bottom boundary layers over relatively homogenous beds have observed logarithmic velocity profiles that support the law of the wall (Gross and Nowell 1983, 1985), but more often observations of boundary layer flow reveal more complex structures with multiple relevant length scales associated with inhomogeneous bed roughness and form drag (Chriss and Caldwell 1982; Gross 1999; Sanford and Lien 1999) and stratification (Perlin et al. 2005b; Trowbridge et al. 1999).

Here, we present observations of turbulence from moored instruments in the turbulent bottom boundary layer (TBBL) on Conch Reef, located at the edge of the southeast Florida shelf, from July and August 2005. During the summer months, the outer southeast Florida shelf experiences an energetic internal-wave field, where shoaling internal waves often appear in a bore-like form on the shallow reef crest (Leichter et al. 2003, 1996). As we will show below, these events can drive strong flows near the bed and transport dense water upslope resulting in dynamic stratified-shear flows. Unlike microstructure profiles, which provide only a "snapshot" of turbulent conditions on the shelf and are often not deployed in regions very near the bed, this dataset represents an extensive time series of high-frequency velocity and temperature measurements collected to examine the nature of near-bed turbulence in the highly dynamic coastal ocean. These measurements allow us to look at the evolution of the TBBL in a stratified-shear environment and comprise one of the most extensive sets of measurements looking at internal-wave forcing on reefs.

\section{Field site description}

Conch Reef $\left(24^{\circ} 57.0^{\prime} \mathrm{N}, 80^{\circ} 27.3^{\prime} \mathrm{W}\right.$; Fig. 1) is located within the Florida Keys National Marine Sanctuary on the edge of the southeast Florida shelf. The benthic community includes scleractinian corals, sponges, hydrozoans, and macroalgae encrusting a carbonate platform. The axis of the Florida Current, with core velocities up to and sometimes exceeding $2.0 \mathrm{~m} \mathrm{~s}^{-1}$ to the northeast, typically lies 5-10 km offshore of the shelf and strongly influences currents on Conch Reef (Davis et al. 2008). Barotropic tidal currents in the Straits of Florida are mixed semidiurnal and relatively small in amplitude (3-5 $\mathrm{cm} \mathrm{s}^{-1}$ ) (Kielmann and Duing 1974). The interaction of the barotropic tidal currents with the topography of the straits produces an energetic internal tidal field (Parr 1937; Schmitz and Richardson 1968). A series of studies by Leichter et al. $(2003,2005,1996,1998)$ and work by Davis et al. (2008) have documented the presence of internal waves shoaling on Florida Keys Reef Tract. These observations revealed highly nonlinear waves associated with the semidiurnal tide and diurnal-period instabilities in the Florida Current, which often take the form of bottom-propagating bores on the reef.

\section{Measurements}

The measurements described in this paper were collected near Aquarius, an underwater laboratory located at 19-m depth on Conch Reef. We used Aquarius as a platform to deploy and monitor an instrument array that continuously collected high-frequency turbulent momentum and heat flux data in a vertical profile in the TBBL. From 13 to 20 July and from 17 to 21 August 2005 approximately $200 \mathrm{~h}$ of boundary layer turbulence measurements were made over a gradually sloping $(\sim 2 \%)$ forereef in $15 \mathrm{~m}$ of water (Fig. 1).

Velocity measurements were collected using a set of four Nortek acoustic Doppler velocimeters (ADVs) mounted on a sawhorse frame located at $0.25,0.60,1.5$, and $3.0 \mathrm{~m}$ above the bed (denoted as ADV 1, 2, 3, and 4, respectively; see Fig. 2a). ADVs 1 and 2 were oriented 


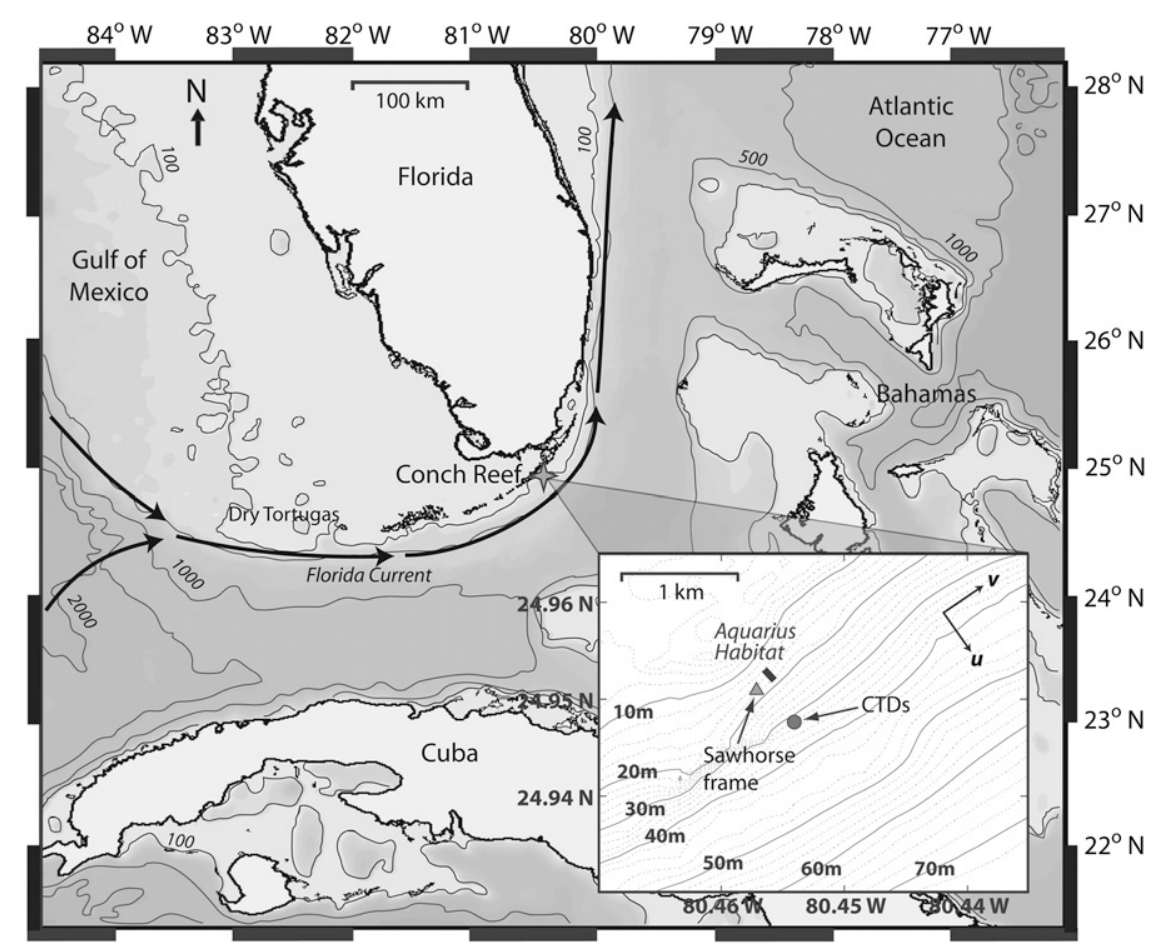

FIG. 1. Map of the Straits of Florida region, indicating the location of Conch Reef on the southeast Florida shelf. Contours are in meters. Inset map is an enlargement of the study site with contoured bathymetry and the location of bottom boundary layer measurements. Contours on the inset map are in 2-m intervals.

downward looking, and ADVs 3 and 4 were oriented facing upward. Precision Measurement Engineering, Inc. (PME) fast-response thermistor sensors (FP07) were laterally positioned approximately $1 \mathrm{~cm}$ from the sampling volume of ADVs 2-4 (Fig. 2b). The ADVs and thermistors were sampled at $32 \mathrm{~Hz}$ and operated over the entire experiment except for times when the data collection was halted for data backup resulting in data gaps of approximately $5 \mathrm{~min}$ with the exception of a 15-h data gap on 19 July due to a power failure. The fastresponse thermistor paired with ADV 3 flooded early in the July experiment, and the thermistor paired with ADV 2 was not operational during the August experiment. Temperature sensors embedded within the ADV end cap were used to estimate buoyancy frequency and turbulent parameters in the bottom boundary layer. A discussion of measurement uncertainties is included in the appendix.

Velocity profiles were collected with an upwardlooking $1200-\mathrm{kHz}$ ADCP with $0.25-\mathrm{m}$ bins from 1 to $13 \mathrm{~m}$ above the bed (mab). The ADCP was located approximately $30 \mathrm{~m}$ south of the sawhorse frame (in a similar cross-shelf position). Velocities from the ADVs and the ADCP were rotated into local alongshelf $\left(v ; 45^{\circ}\right)$, across-shelf $\left(u ; 135^{\circ}\right)$, and vertical components $(w)$.
Time series measurements of temperature on the reef slope were obtained using vertical arrays of Seabird Electronics SBE-39 temperature sensors located 0, 4, 8, and $12 \mathrm{mab}$, deployed on a taut line approximately $15 \mathrm{~m}$ south of the sawhorse frame, and sampled at 1-min intervals. Additionally, a vertical array of CTDs was moored approximately $500 \mathrm{~m}$ southeast (offshore) of the sawhorse frame in 32-m water depth. Data from three CTDs located approximately near the top, middle, and bottom of the water column were used to derive a relationship between temperature and salinity for water masses on the reef, allowing for the estimation of density from temperature sensors at the 15-m mooring and from temperature recorded by the ADVs (see appendix). Wave statistics were measured with a Seabird Electronics SBE-26 wave and tide gauge mounted $2 \mathrm{mab}$ on the sawhorse frame. All times refer to local time, eastern daylight time [EDT $=$ coordinated universal time (UTC) $-4 \mathrm{~h}]$.

Small-scale surveys of physical bed roughness were conducted by divers along six transects near the sawhorse frame using a modification of a roughness measurement scheme outlined by McCormick (1994). Roughness height on the reef ranged from 11 to $35 \mathrm{~cm}$ with an average of $20 \mathrm{~cm}$. 


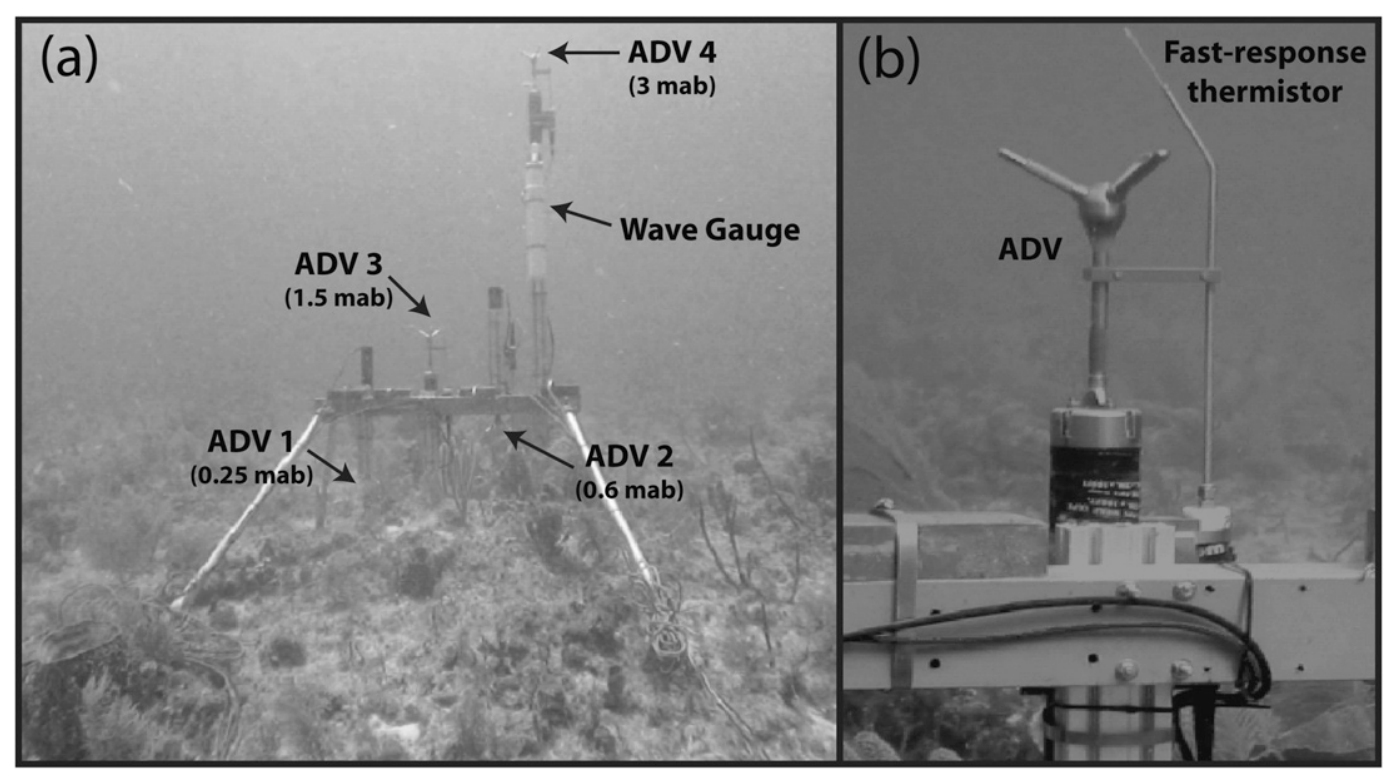

FIG. 2. Experimental setup on Conch Reef, July-August 2005. (a) Sawhorse frame with four Nortek vector ADVs, three PME fast-response thermistors, and an SBE-26plus tide and wave gauge. (b) Close-up image of one ADV-thermistor coupling.

\section{Analyses}

ADV and fast-response thermistor data were processed into 10-min intervals, and several quality control tests were applied before the calculation of turbulence statistics. First, to check that the orientation of the ADV instrument coordinate system was close to the true coordinate system over the sloping bed, we required that the ensemble-averaged vertical velocity was less than $1 \mathrm{~cm} \mathrm{~s}^{-1}$. Second, a nonparametric reverse arrangements test was applied to time-averaged and fluctuating velocity and temperature data to ensure the statistical stationarity of these quantities within each ensemble (Bendat and Piersol 2000, section 4.5.2). Third, segments of the ADV data ranging from 2 to $60 \mathrm{~s}$ in length were contaminated by reef fish swimming between the transducers. This phenomenon was observed on several occasions by divers and can be identified in the velocity data when large-magnitude, high-frequency fluctuations coincide with extremely high backscatter intensity. Contaminated ADV data segments were replaced with white noise scaled by the ensemble velocity variance, which has a flat spectral signature. Ensembles with more than $10 \%$ of the data contaminated by "fish noise" were not included in the analysis.

Fourth, the sawhorse frame was positioned with the top horizontal beam oriented in the alongshelf direction to minimize leg wakes from surface-wave-driven flow. Despite precautions, velocity data from ADV 2 were contaminated by frame interference during periods of downcoast flow (toward the southwest) and were not included in the final analysis. Finally, an important consideration in the calculation of turbulent statistics is the presence of stratification and wave-induced perturbations that can contaminate the estimation of momentum and density fluxes and dissipation. We considered the effect of surface waves in dissipation estimates using a kinematic model for the effect of surface waves on the turbulent spectrum and in momentum and buoyancy flux estimates using a method of differencing the signals between adjacent sensors, neither of which explicitly accounts for waveturbulence interactions [last two terms on the left-hand side of Eq. (1)]. Detailed procedures for the calculation of these turbulent statistics, including an analysis of the quality of estimates in the presence of stratification and surface-wave forcing and uncertainty are included in the appendix.

The state of turbulence in a stratified-shear flow can be characterized by average properties of local shear $S^{2}=(\partial U / \partial z)^{2}+(\partial V / \partial z)^{2}$ and stratification $N^{2}=-(g / \rho)$ $(\partial \rho / \partial z)$ in the gradient Richardson number $\mathrm{Ri}_{g}=N^{2} / S^{2}$. It is generally thought that, if $\mathrm{Ri}_{g}$ everywhere in the flow is greater than the critical value of 0.25 , the flow is stable against small-amplitude fluctuations (Miles 1961) and turbulent mixing is restricted (Rohr et al. 1988). If the value of $\mathrm{Ri}_{g}<0.25$ somewhere in the flow, instabilities can grow, yielding a region of active turbulence. Below, we discuss $\mathrm{Ri}_{g}$ estimates on Conch Reef, calculated from ADV velocity and temperature data and will also refer to the normalized Richardson number, 


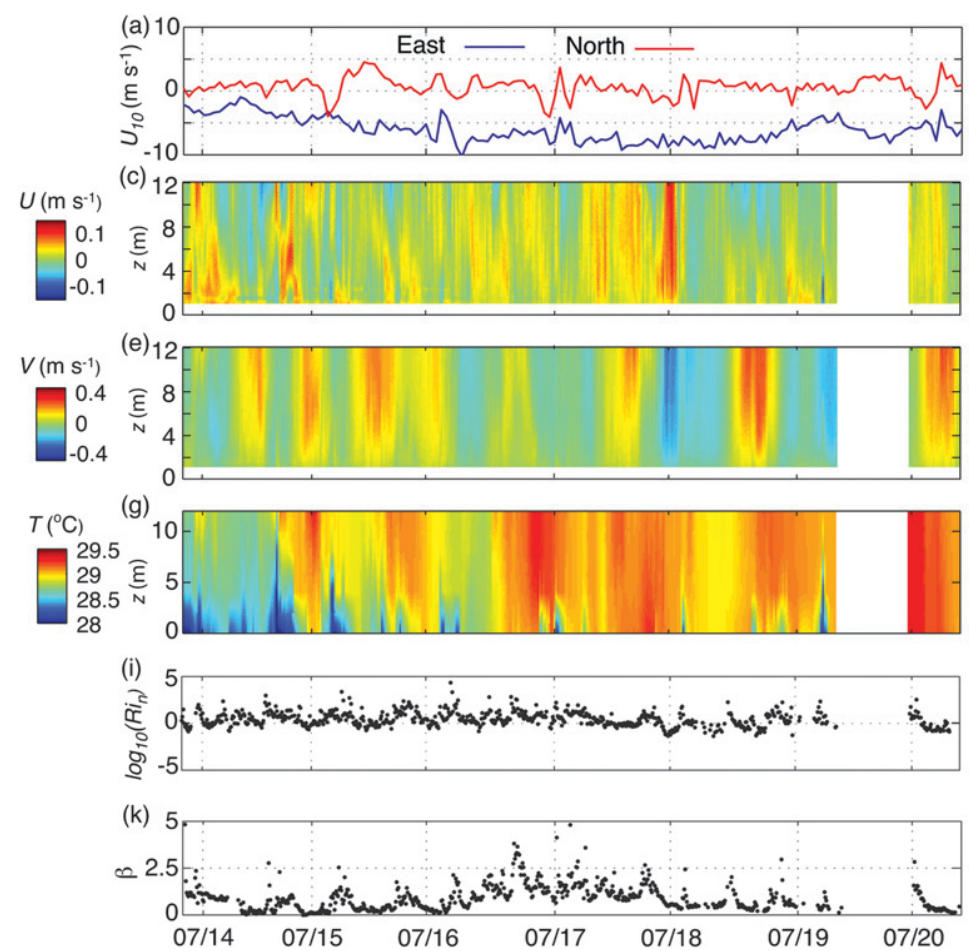

(b)

(d)

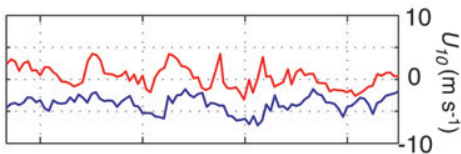

d)

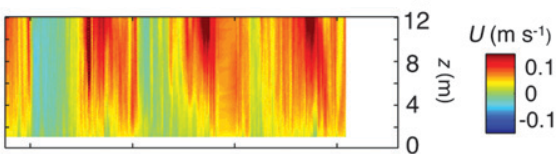

(f)

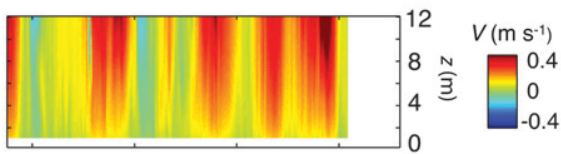

(h)

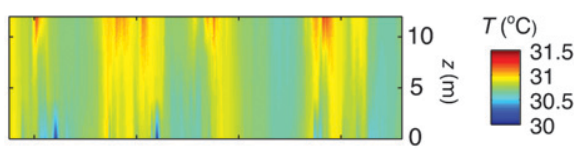

(j)

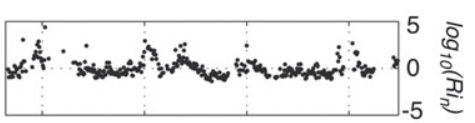

(l)

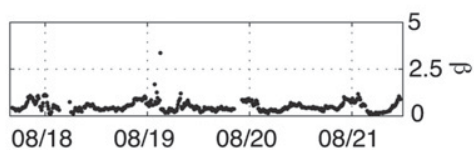

FIG. 3. (left) July and (right) August 2005 time series of (a),(b) hour-averaged wind speed to the east and north; 10-min-averaged (c),(d) across-shelf velocities, (e),(f) alongshelf velocities, and (g),(h) water temperature [note the difference in color axes between (g) and (h)]; (i),(j) logarithm of the normalized gradient Richardson number near the bed; and (k),(l) $\beta_{u}$, the ratio of wave orbital velocity to the ensemble-averaged across-shelf velocity, measured at ADV 4 (3 mab).

$$
\mathrm{Ri}_{n}=\frac{\mathrm{Ri}_{g}}{0.25} .
$$

Estimates of $\mathrm{Ri}_{g}$ were calculated over the vertical distance between ADVs from the ensemble-averaged shear and stratification.

\section{Observations}

\section{a. Mean flow and wave conditions}

Currents on the outer southeast Florida shelf are heavily influenced by the nearby Florida Current (Davis et al. 2008; Lee 1986). Flow is primarily oriented in the alongshelf direction, but there is often an offshore current $(+u)$ associated with a strong flow upcoast $(+v)$, which can be seen in the August time series (Figs. 3d,f). During the July study (Figs. 3c,e), currents are more variable and are punctuated by a large-amplitude oscillation with a period of strong downcoast flow (to the southwest) late on 17 July and early on 18 July that is characteristic of the passage of a Florida Current frontal eddy (Lee 1975). A time series of water temperatures on Conch Reef (Figs. 3g,h) indicates a general warming trend throughout the July experiment and high-frequency pulses of cool water near the bed, which are associated with shoaling internal waves. In August, the water column was much warmer and there were very few near-bed cooling events. Figures $3 \mathrm{i}, \mathrm{j}$ display $\log _{10}\left(\mathrm{Ri}_{n}\right)$ averaged over all ADVs, such that values near zero indicate a nearcritical state. Positive peaks in $\log _{10}\left(\mathrm{Ri}_{n}\right)$ are associated with periods of near-bed cooling, suggest that, during these events, turbulence in the bottom $3 \mathrm{~m}$ was strongly affected by stratification.

Hour-averaged wind data for July and August 2005, obtained from the National Buoy Data Center CoastalMarine Automated Network (C-MAN) station on Molasses Reef (\#MLRF1), $10 \mathrm{~km}$ from Conch Reef, showed an average wind speed of $5 \mathrm{~m} \mathrm{~s}^{-1}$ directed to the northwest (Figs. 3a,b). Local wind forcing does not correlate significantly with currents on the reef, consistent with previous studies in the upper Florida Keys that have found local wind forcing to be a small factor in flows on the outer shelf during summer (Davis et al. 2008; Lee 1986).

At the study site, surface waves propagated onshore without breaking. Significant wave height $H_{\text {sig }}$ ranged from 0.3 to $1.3 \mathrm{~m}$, and the peak period ranged from 4.5 to $5.5 \mathrm{~s}$. Surface-wave orbital velocities, estimated as the standard deviation of horizontal velocity components 

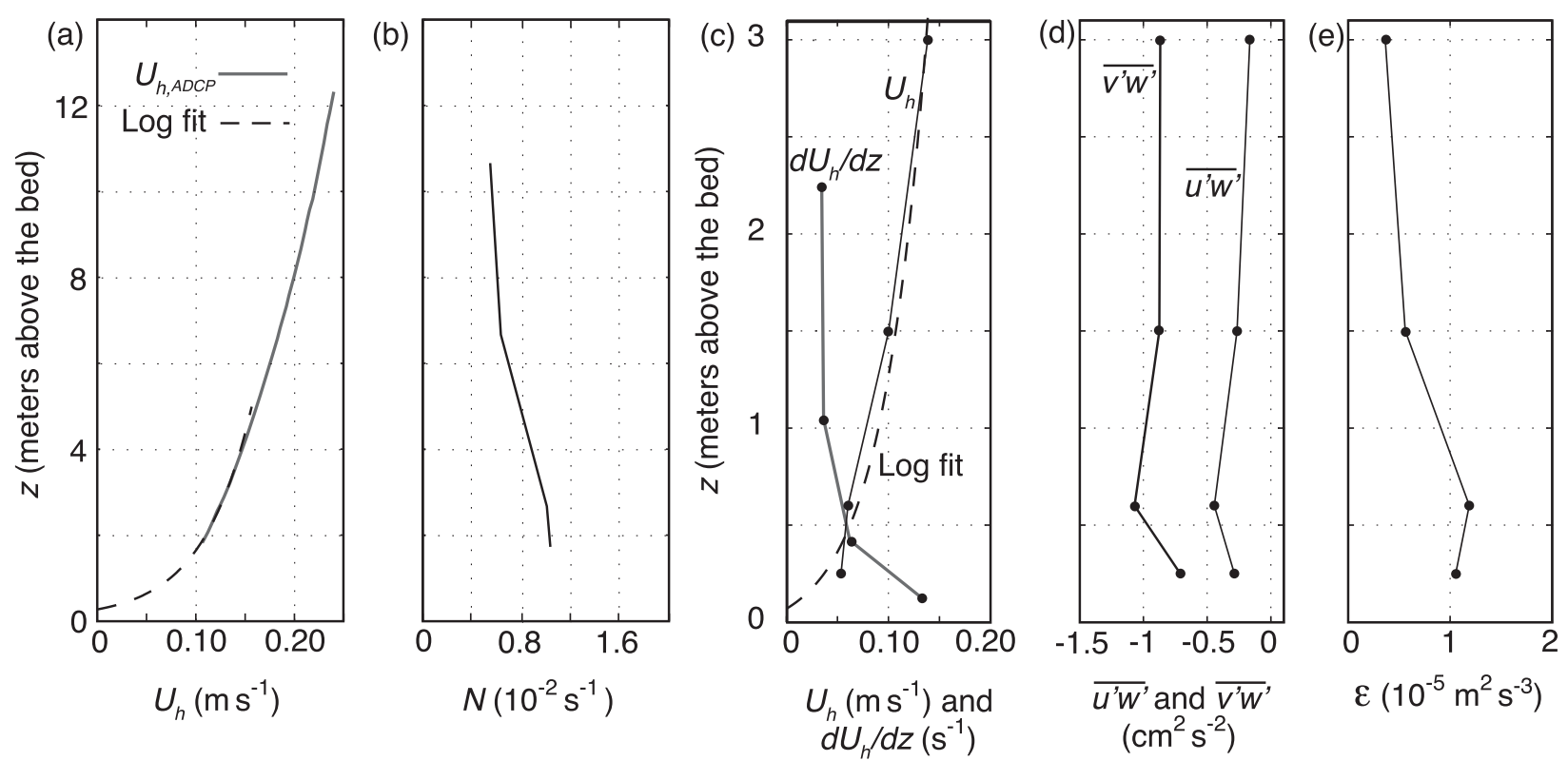

FIG. 4. Vertical profiles of mean currents, stratification, and turbulent quantities averaged over 242 ensembles in the alongshelf regime: (a) $U_{h}=\left(U^{2}+V^{2}\right)^{1 / 2}$ measured by ADCP (solid line) and logarithmic fit (dotted line) from the lowest bin to 5 mab; (b) buoyancy frequency; (c) $U_{h}$ (solid black line), logarithmic fit (dotted line), and mean shear $\partial U_{h} / \partial z$ (solid gray line) measured by ADVs; (d) Reynolds stresses; and (e) viscous dissipation. Note that the vertical axes of (a) and (b) extend over the entire water column, whereas (c)-(e) are quantities derived from ADV measurements in the bottom $3 \mathrm{~m}$. The $90 \%$ confidence intervals for the quantities in (c)-(e) were in all cases smaller than the data markers.

within each ensemble $\sigma_{u_{h}}$, where $u_{h}=\sqrt{u^{2}+v^{2}}$, had average values of $6 \mathrm{~cm} \mathrm{~s}^{-1}$ at ADV 1 and $10 \mathrm{~cm} \mathrm{~s}^{-1}$ at ADV 4. A time series of $\beta=\sigma_{u_{h}} / U_{h}$ (Figs. 3k,1), the ratio of wave orbital velocity to $U_{h}$, the mean horizontal flow speed, illustrates the importance of surface-waveinduced velocity variance in the TBBL, with values often greater than one.

\section{b. Boundary layer turbulence regimes}

Although near-bed turbulence on the reef was highly variable in time, the boundary layer turbulence observed on Conch Reef can be grouped into three regimes, characterized by the direction of flow near the bed: an alongshelf flow regime where mean velocities near the bed are aligned with the local isobaths and the near-bed region is relatively well mixed (this regime is typically not coincident with periods of shoaling internal waves on the reef slope); an onshore flow regime, which often marks the onshore surge of a nonlinear internal wave and is accompanied by cooling water temperatures and an increase in stratification near the bed; and an offshore flow regime, where warming temperatures, intense stratification, and a jet-like velocity structure near the bed are the result of the relaxation and downslope flow of dense water following the onshore surge. To examine each of the regimes, ensembles were binned according to the characteristics described above, resulting in 242 alongshelf ensembles, where $V>5 \mathrm{~cm} \mathrm{~s}^{-1}$ and $|U|<$ $2 \mathrm{~cm} \mathrm{~s}^{-1} ; 43$ onshore ensembles, where $|U|<-2 \mathrm{~cm} \mathrm{~s}^{-1}$ and $|V|<5 \mathrm{~cm} \mathrm{~s}^{-1}$; and 157 offshore ensembles, where $U>2 \mathrm{~cm} \mathrm{~s}^{-1}$ and $|V|<5 \mathrm{~cm} \mathrm{~s}^{-1}$.

\section{1) Alongshelf Flow}

During typical alongshelf flow conditions, the vertical profile of mean horizontal velocity measured by the ADCP resembles that which might be expected for neutral boundary layer flow (Fig. 4a, where $U_{h}$ is averaged over all alongshelf ensembles). A logarithmic velocity profile,

$$
U(z)=\frac{u_{*}}{\kappa} \ln \frac{z}{z_{0}},
$$

defined by the friction velocity $u_{*}$ and roughness length $z_{0}$, was fit to the average alongshelf velocity profile from the lowest bin to $5 \mathrm{mab}$ (14 data points), resulting in $u_{*}=$ $2.1 \pm 0.1 \mathrm{~cm} \mathrm{~s}^{-1}$ and $Z_{0}=22 \pm 2 \mathrm{~cm}$ (where confidence intervals are at the $90 \%$ level). Here, $\kappa$ is the von Kármán constant, 0.41 .

The near-bed velocity profile (Fig. 4c) displays a departure from the logarithmic shape in the bottommost meter of the water column, and profiles of Reynolds stresses (Fig. 4d) peak at ADV 2. This distorted vertical flow structure could be due to shear created at the top of the reef "canopy" and in the wakes of individual canopy 
elements (Finnigan 2000), or it could be an effect of the oscillatory surface-wave-driven flow (Mellor 2002). The friction velocity estimated from the Reynolds stresses is $1 \mathrm{~cm} \mathrm{~s}^{-1}$, roughly half of the magnitude predicted by the logarithmic profile. This discrepancy may be attributed to the combined effects of sensor resolution, acceleration effects, and pressure gradients, which can all act to reduce Reynolds stress estimates away from the bottom (Gross and Nowell 1985) or to the modification of the logarithmic region by stratification (Perlin et al. 2005b). The vertical profile of turbulent dissipation (Fig. 4e) mirrors the Reynolds stress profile and is maximal near the bed. Dissipation measurements at ADVs 2-4 agree well with classic bottom boundary layer scaling for dissipation, $\varepsilon=u_{*}^{3} / \kappa z$ (Grant and Madsen 1986), where $u_{*}$ is predicted from the logarithmic profile method (Figs. 5a-c). However, bottom boundary layer scaling overpredicts the dissipation at ADV 1 (Fig. 5d), which is expected if the sensor is within the canopy and below the "constant stress" layer.

To compute the coefficient of drag $C_{D}$,

$$
C_{D}=u_{*}^{2} / U_{1 \mathrm{~m}}^{2},
$$

we used $u_{*}$ based on the eddy-covariance method from ADV stress measurements at 0.6 mab and computed $U_{1 \mathrm{~m}}$ by linearly interpolating the ADV ensemble-averaged speed to a location 1 mab (Sanford and Lien 1999). A best-fit line was found using least squares regression on the alongshelf ensembles to minimize the effect of internal waves, including only ensembles where $U_{1 \mathrm{~m}}>$ $5 \mathrm{~cm} \mathrm{~s}^{-1}$. The line was constrained to go through the origin so that $u_{*}=0$ when $U_{1 \mathrm{~m}}=0 . C_{D}$ was estimated to be $0.017 \pm 0.001$, which is much larger than the canonical value for sand and mud bottoms ( 0.0025 ; Gross and Nowell 1983), but comparable to values of $C_{D}$ found using similar methods (0.009-0.015) over coral substrates in Eilat, Israel, by Reidenbach et al. (2006).

\section{2) ACROSS-SHELF FLOW}

Internal waves on Conch Reef, regardless of their original form or generation mechanism, are generally nonlinear on the shallow shelf and are characterized by onshore surges of cool, nutrient-rich water near the bed, often taking the form of an internal bore (Davis et al. 2008; Leichter et al. 1996). An internal-wave event measured on the reef on 15 July 2005 (Fig. 6) is illustrative of turbulent dynamics in the TBBL over the reef during a period of internal-wave activity. The temperature record (Fig. 6c) reveals a series of near-bed thermal fronts superimposed on a lower-frequency oscillation representing the subsurface intrusion of cool water onto the shelf from the internal tide. The largest cold-water fronts at 0100 and
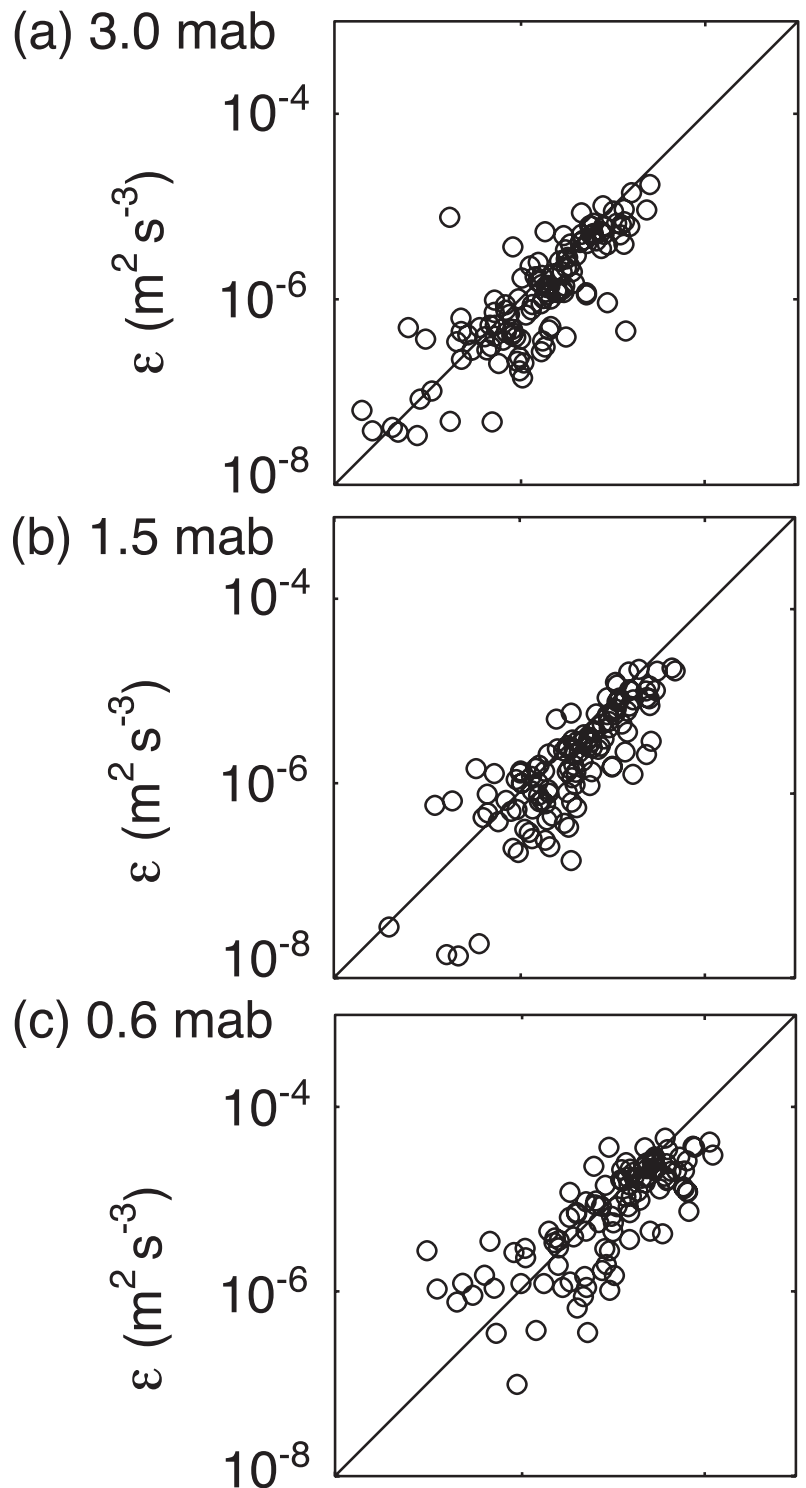

(d) $0.25 \mathrm{mab}$

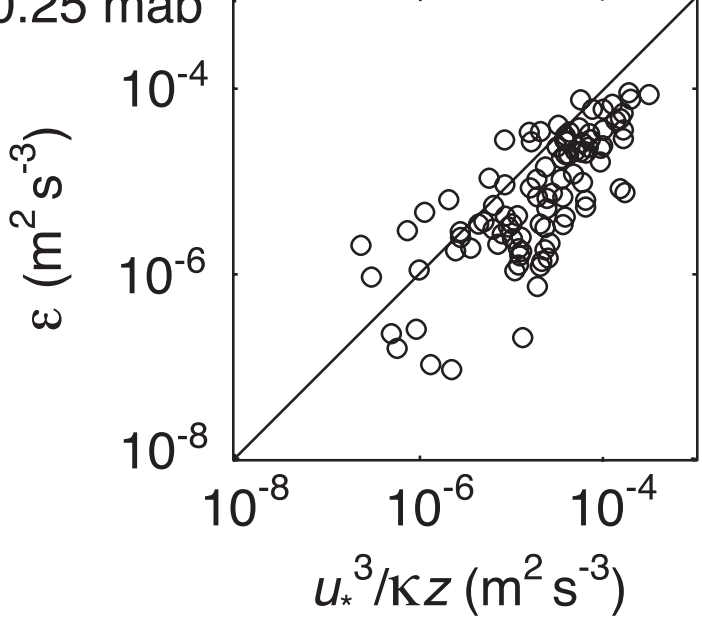

FIG. 5. Observed dissipation $\varepsilon$ vs bottom boundary layer scaling $u_{*}^{3} / \kappa z$ at (a) ADV 4, (b) ADV 3, (c) ADV 2, and (d) ADV 1. 
(a) $U\left(\mathrm{cms}^{-1}\right)$
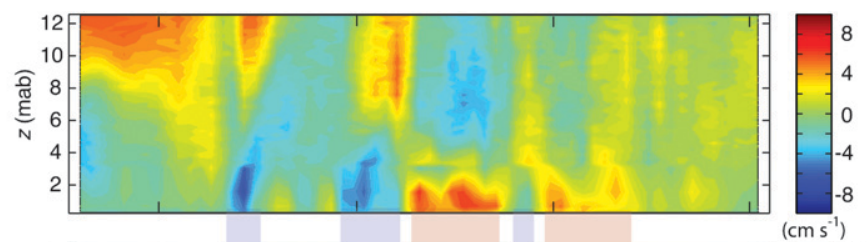

(b) $V\left(\mathrm{~cm} \mathrm{~s}^{-1}\right)$
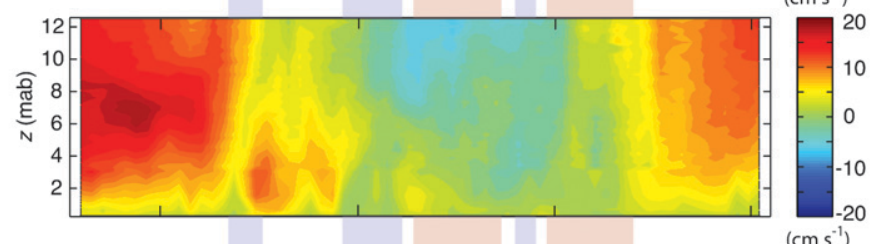

(c) $T\left({ }^{\circ} \mathrm{C}\right)$

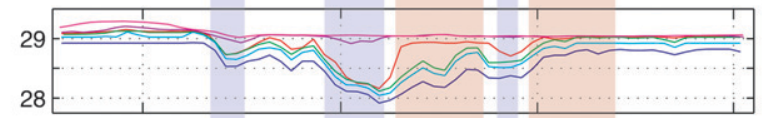
$\left(\mathrm{cm} \mathrm{s}^{-1}\right)$

(d) $\log _{10}(\varepsilon)$ $\left(m^{2} s^{-3}\right)$

(e) $\log _{10}(P)$ $\left(m^{2} s^{-3}\right)$
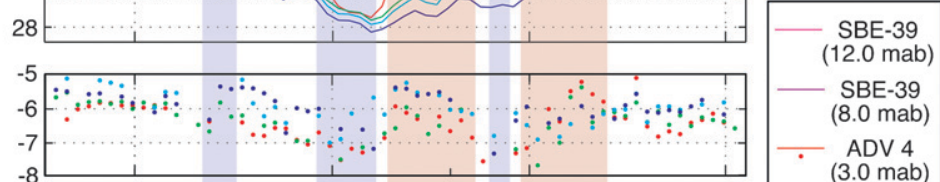
(12.0 mab)

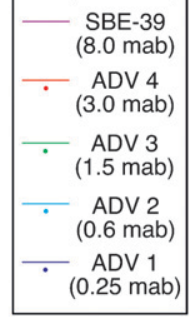
(f) $B\left(\mathrm{~m}^{2} \mathrm{~s}^{-3} \times 10^{-7}\right)$
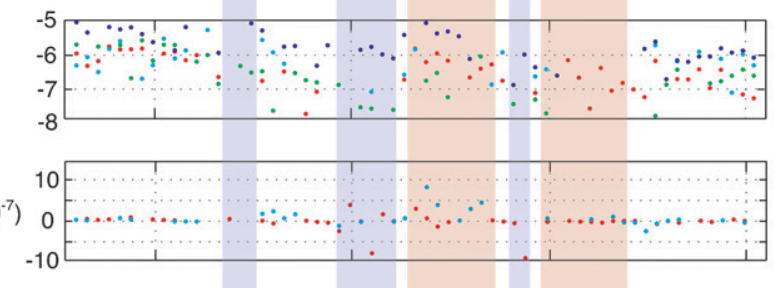
ADV 3

(g) $\log _{10}\left(R i_{n}\right)$

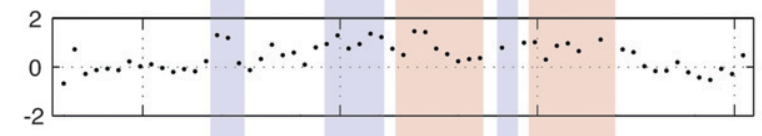

(h) Turbulence length scales

(m)

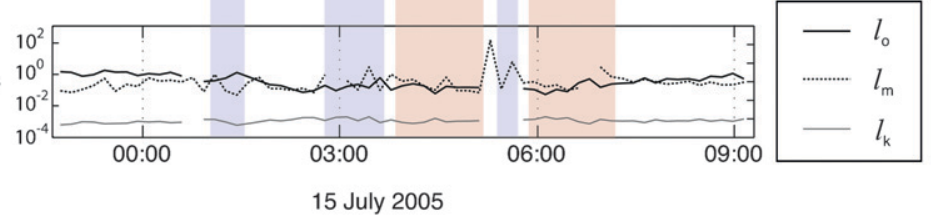

FIG. 6. Time series of (a) across-shelf and (b) alongshelf ensemble-averaged currents compiled from ADV (0.25-3 mab) and ADCP (3-12 mab) measurements; (c) temperature; (d) logarithm of turbulent dissipation $\varepsilon$; (e) logarithm of shear production $P$; (f) buoyancy flux $B$; (g) logarithm of the normalized gradient Richardson number $\mathrm{Ri}_{n}$; and (h) Ozmidov $\left(l_{o}\right)$, mixing $\left(l_{m}\right)$, and Kolmogorov $\left(l_{k}\right)$ turbulence length scales estimated at 1.05 mab for a typical internal-wave event on Conch Reef on 15 Jul 2005.

$0250 \mathrm{LT}$ were accompanied by pulses of onshore flow $(-U$ in Fig. 6a) in the bottom $4 \mathrm{~m}$ of the water column and a reduction in the along-shelf flow (Fig. 6b). Subsequently, periods of strong offshore flow $(+U$ in Fig. 6a) and warming water temperature in the near-bed region indicate a relaxation of the cold-water mass back down the reef slope. For visualization purposes, periods of onshore and offshore flow near the bed are highlighted in Figs. $6 \mathrm{c}-\mathrm{h}$ with blue and orange shading, respectively. Vertical profiles of across-shelf velocity, shear, stratification, and turbulent quantities are averaged over the onshore and offshore flow regimes during the 15 July internal-wave event and are shown in Fig. 7.
In addition to transporting cool water masses to the reef, these shoaling internal waves can significantly change bottom boundary layer structure, increasing nearbed flow speed, shear, and turbulent dissipation. Average flow speed at ADV 1 and 2 during periods of across-shelf flow (both onshore and offshore flow regimes) was found to be $41 \%$ and $33 \%$ higher, respectively, than during periods of primarily alongshelf near-bed flow, before and after the internal-wave event. The same was true for mean shear, calculated between ADV 1 and 2, which was $36 \%$ larger during periods of internal-wave-driven across-shelf flows. ADV 3 and 4, however, experienced maximum flow speed and shear in the alongshelf flow 

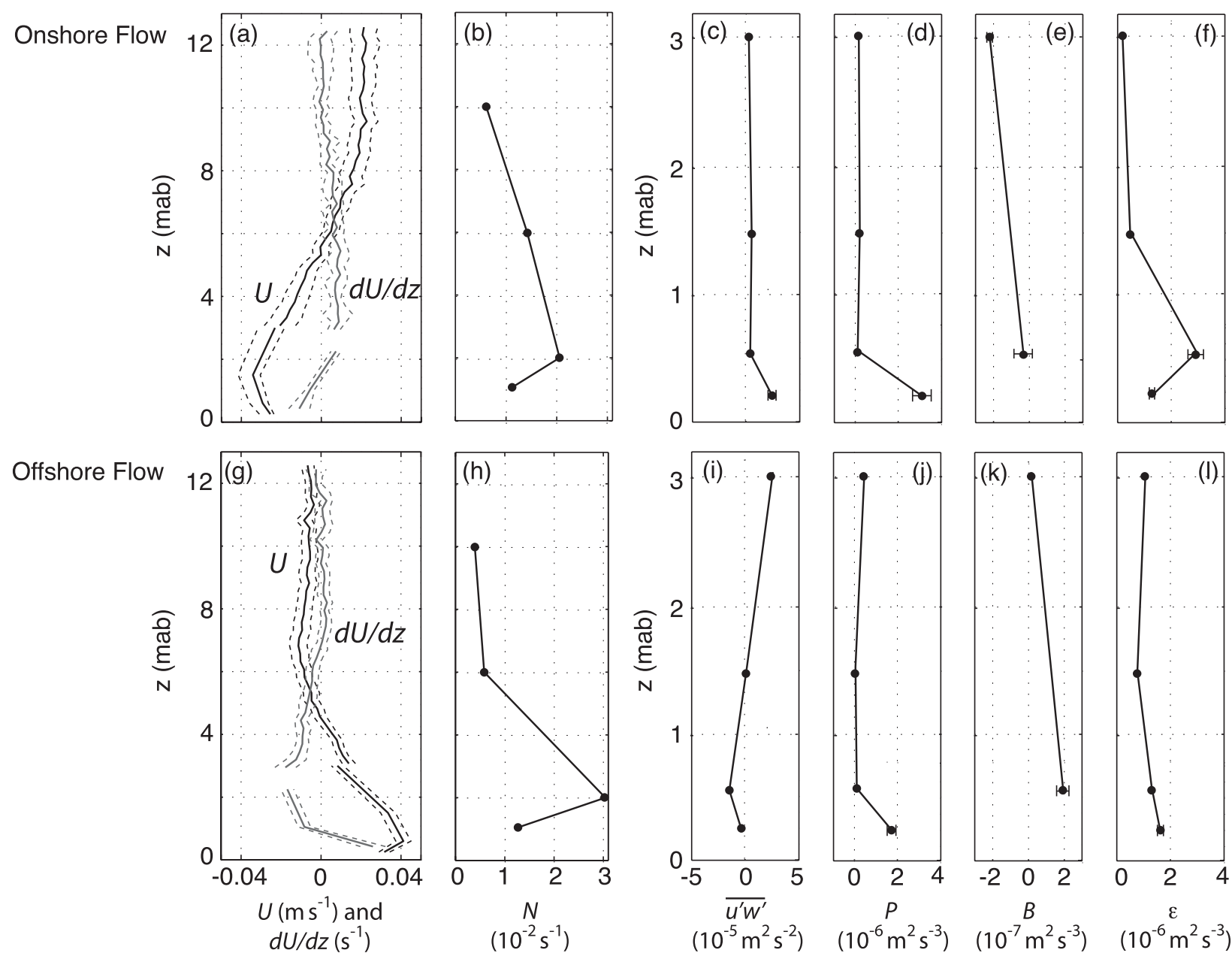

FIG. 7. (left to right) Vertical profiles of mean currents, stratification, and turbulent quantities averaged over (a)-(f) 11 onshore ensembles and (g)-(1) 19 offshore ensembles during the 14-15 Jul 2005 internal-wave event. Here, (a) and (g) are mean across-shelf flow $\bar{u}$ (black line) and shear $d \bar{u} / d z$ (gray line) measured by both the ADCP and ADVs, and (b) and (h) are the average buoyancy frequency estimated from the vertical array of temperature sensors. Also, (c) and (i) are the across-shelf component of Reynolds stress, (d) and (j) are the shear production of turbulence, (e) and (k) are the buoyancy flux, and (f) and (l) are the viscous dissipation of turbulence measured in the bottom $3 \mathrm{~m}$ by ADVs. The $90 \%$ confidence intervals are shown unless they are smaller than the data marker.

regime. Turbulent dissipation in the bottom meter was also greatest during periods of across-shelf near-bed flow, with values at ADV $140 \%$ larger and at ADV $228 \%$ larger than values averaged over alongshelf flow ensembles during the 15 July event. Strong gradients in shear, stratification, and turbulent quantities near the bed (Fig. 7) indicate the presence of stratified-shear layers.

Profiles of Reynolds stress averaged over onshore and offshore regimes during the 15 July event (Figs. 7c,i) exhibit a different vertical structure than that observed in the TBBL during alongshelf flow (Fig. 4d). During offshore flow, Reynolds stress peaks at ADV 2, similarly to alongshelf flow, but changes sign at ADV 3 and 4, indicating an upward flux of momentum from the nearbed jet of dense water flowing offshore. During onshore flow, Reynolds stress peaks near the bed and is very weak above ADV 1, suggesting that the bottom mixed layer is very thin during the initial onshore surge of dense water from shoaling internal waves.

Observations of buoyancy flux during the July and August experiments yielded values that were generally negligible compared to $P$ and $\varepsilon$; however, during periods of internal-wave shoaling on the reef, $B$ increased in magnitude but even still was highly intermittent. A time series of $B$ measurements during the 15 July internalwave event (Fig. 6f) shows both positive and negative values of buoyancy flux. A downgradient buoyancy flux $(+B)$ represents the upward transport of dense fluid (or downward transport of lighter fluid) and is expected in stable stratification. However, previous field studies in 

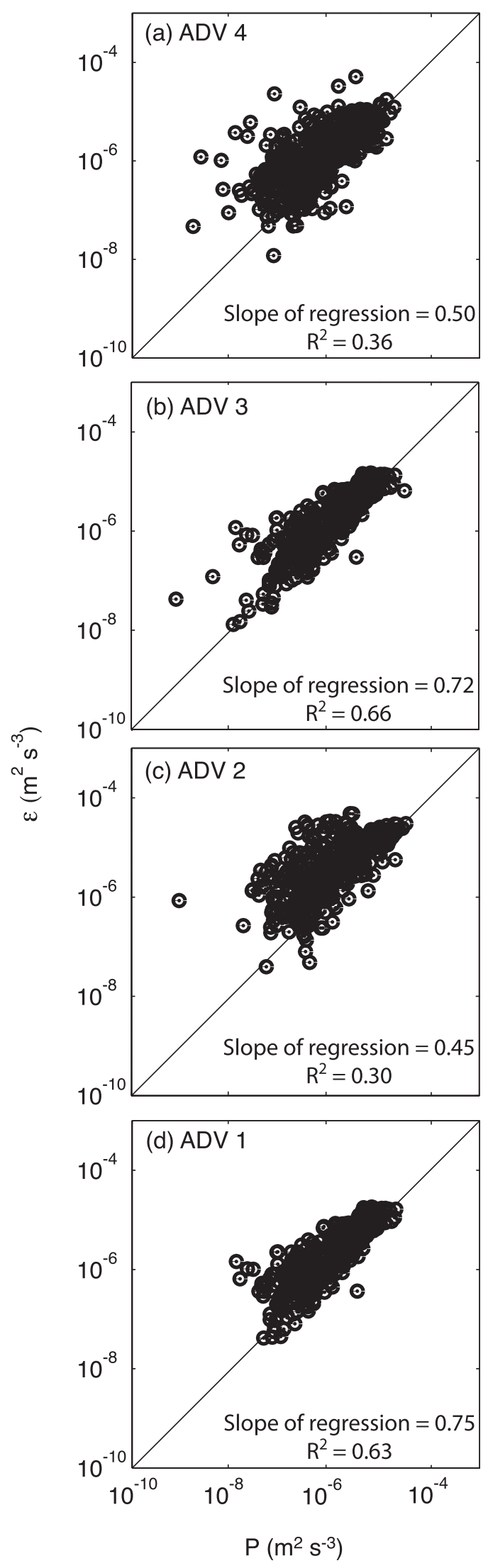

lakes (Etemad-Shahidi and Imberger 2001) and in the ocean thermocline (Moum 1996) observed upgradient buoyancy fluxes $(-B)$ as frequently as downgradient fluxes. Here, $B$, averaged over periods of offshore flow during the 15 July event, was downgradient and peaked near the bed at $2 \times 10^{-7} \mathrm{~m}^{2} \mathrm{~s}^{-3}$ (Fig. 7k). Interestingly, the average of $B$ over onshore flow periods (Fig. 7e) is dominated by two relatively large negative values (approximately $-1 \times 10^{-6} \mathrm{~m}^{2} \mathrm{~s}^{-3}$ ) that occur at ADV 4 during the weaker second and third onshore surges. These $-B$ events may result from convective mixing or local restratification associated with buoyancy anomalies produced by the interaction between the shoaling and retreating internal waves (Taylor 1993) or the differential transport of stratified water masses along a rough slope (Lorke et al. 2005; Lorke et al. 2008).

The value of $\mathrm{Ri}_{g}$ was calculated over the bottom $3 \mathrm{~m}$ of the water column during the 15 July internal-wave event and is plotted as $\log _{10}\left(\mathrm{Ri}_{n}\right)$ in Fig. $6 \mathrm{~g}$. During the periods of alongshelf flow near the bed, $\mathrm{Ri}_{g}$ is near critical and at times less than the critical value, whereas, during periods of onshore and offshore flow near the bed, $\mathrm{Ri}_{g}$ is above the critical value, indicating that nearbed stratification during shoaling internal waves can be strong enough to significantly effect TBBL dynamics.

To test the concept of a local equilibrium in the TKE balance, Eq. (1), we present scatterplots of $\varepsilon$ versus $P$ for instruments at all heights and for data in both alongshelf and cross-shelf regimes (Fig. 8). Although $P$ and $\varepsilon$ are generally within an order of magnitude of each other, on average, turbulent dissipation exceeds turbulent shear production, with $P \sim 0.7 \varepsilon$. The inclusion of $B$ in the TKE budget does not significantly improve the balance between turbulent production and sink terms. Our findings differ from observations of boundary layer turbulence over a fringing coral reef in the Gulf of Aqaba by Reidenbach et al. (2006), who found a local balance between $P$ and $\varepsilon$ at locations $0.1,0.3$, and 1 mab.

One possible explanation for elevated levels of dissipation in our measurements is the horizontal advection of TKE. This explanation seems likely because of the extreme roughness and irregularity of the reef bedforms. Under these conditions, our findings of an imbalance between $P, \varepsilon$, and $B$ seem reasonable, but it is important to emphasize that the commonly employed assumption of a well-mixed boundary layer and the local balance of

FIG. 8. Turbulent dissipation $\varepsilon$ vs shear production $P$ for (a) ADV 4 (3 mab), (b) ADV 3 (1.5 mab), (c) ADV 2 (0.6 mab), and (d) ADV 1 (0.25 mab). Data markers include confidence interval. 
turbulent production and dissipation do not hold for our observations of stratified TBBL flow over a rough bed.

\section{Discussion}

\section{a. Length scales of turbulence}

The nature of turbulence in a stratified environment can be examined by estimating length scales that characterize the relative importance of forces shaping the turbulent field. Here, we discuss three characteristic length scales. First, the Prandtl mixing-length scale,

$$
l_{m}=\left(\frac{\overline{u^{\prime} w^{\prime}}}{S^{2}}\right)^{1 / 2}
$$

is an estimate of the size of energy-containing turbulent eddies derived from Prandtl's mixing-length hypothesis (Prandtl 1925). Stable stratification provides an upper limit to the growth of turbulent eddies and is characterized by the Ozmidov length scale,

$$
l_{o}=\left(\frac{\varepsilon}{N^{3}}\right)^{1 / 2} .
$$

The largest eddies transfer energy through the turbulent cascade to smaller eddies until molecular viscosity $\nu$ dissipates the energy at the smallest scales, represented by the Kolmogorov length scale,

$$
l_{k}=\left(\frac{\nu^{3}}{\varepsilon}\right)^{1 / 4}
$$

Using these formulations, characteristic length scales were estimated between ADVs at $0.42,1.05$, and 2.25 mab, such that $S$ and $N$ could be directly calculated, whereas $\varepsilon$ and $\overline{u^{\prime} w^{\prime}}$ were averaged between instruments. Characteristic length scales at the height of $1.05 \mathrm{mab}$ are shown in Fig. 6h. Prior to the first onshore surge at $0100 \mathrm{LT}, l_{m}$ was on average $0.3 \mathrm{~m}$, similar in magnitude to another approximation of the Prandtl mixing length, $\kappa z=0.4 \mathrm{~m}$, and $l_{o}$ was much larger, about $2 \mathrm{~m}$, indicating that during this period buoyant forces did not substantially affect the size of turbulent eddies in the TBBL. During the onshore and offshore flow regimes, $l_{o}$ decreased to approximately $0.5 \mathrm{~m}$, responding to the increased near-bed stratification driven by the shoaling internal waves, whereas $l_{m}$ increased slightly and was at times larger than $l_{o}$. The convergence of $l_{o}$ and $l_{m}$ implies that the largest scales of turbulence were being constrained by buoyant forces. After the internal-wave event, near-bed stratification decreased and the difference between $l_{o}$ and $l_{m}$ once again increased. Here, $l_{k}$ was approximately constant over the time series shown and averaged $9 \times 10^{-4} \mathrm{~m}$.

\section{$b$. The efficiency of turbulent mixing}

The vertical mixing of heat and mass in the ocean is traditionally estimated using eddy diffusivity formulations such as that proposed by Osborn (1980),

$$
K_{\rho}=\Gamma \varepsilon N^{-2},
$$

where $\Gamma$ represents the mixing coefficient. Osborn (1980) suggested that a critical value of $\Gamma=0.2$ can be used to represent turbulence which persists in a steady-state flow, among other qualifications.

Direct measurements of $K_{\rho}$ in laboratory experiments and estimates from numerical simulations imply that mixing efficiency is not a constant but that it can vary with stratification (Barrett and Atta 1991; Rehmann and Koseff 2004); the age of a turbulent patch (Smyth et al. 2001); and buoyancy Reynolds number, $\operatorname{Re}_{b}=\varepsilon / \nu N^{2}$, which is also known as turbulence intensity (Barry et al. 2001; Shih et al. 2005). Mixing efficiency can also be represented by the flux Richardson number $R_{f}$, which was defined by Ivey and Imberger (1991) as

$$
R_{f}=\frac{B}{m}=\frac{1}{1+(\varepsilon / B)},
$$

where $m$ is the net mechanical energy available to sustain turbulent motions and includes all terms on the lefthand side of Eq. (1). The terms $\Gamma$ and $R_{f}$ are related as $\Gamma=R_{f} /\left(1-R_{f}\right)$.

Using measurements of $\varepsilon$ and $B$ collected in the TBBL on Conch Reef, we were able to directly estimate $R_{f}$. In this section, we examine the dependence of $R_{f}$ on parameters often used to characterize stratified turbulent flows and test relationships previously found in laboratory and numerical work. Values of $R_{f}$ calculated from all ensembles at ADV 2 and 4 (the only sampling locations with a sufficient record of high-frequency temperature measurements) range from 0 to 0.5 and are represented by the color axis in Fig. 9 in turbulent Reynolds numberturbulent Froude number $\left(\mathrm{Re}_{t}-\mathrm{Fr}_{t}\right)$ parameter space. Here, $\mathrm{Re}_{t}$ represents the range of energy-bearing turbulent scales and can be estimated as

$$
\operatorname{Re}_{t}=\left(\frac{l_{e}}{l_{k}}\right)^{4 / 3},
$$

where

$$
l_{e}=\frac{\rho^{\prime}}{\partial \bar{\rho} / \partial z}
$$




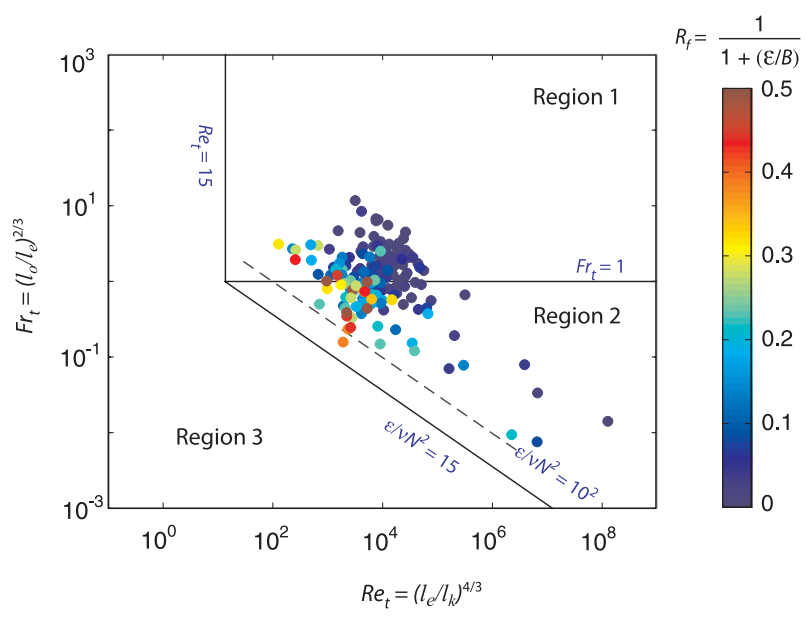

FIG. 9. Turbulent Froude number $\mathrm{Fr}_{t}$ vs turbulent Reynolds number $\mathrm{Re}_{t}$ for all ensembles at ADV 2 and ADV 4. Here, $R_{f}$ is represented by the color axis.

the Ellison length scale, is the overturning scale of turbulence in a density field; $\rho$ ' is the fluctuating component of density; and $\partial \bar{\rho} / \partial z$ is the mean density gradient. The term $\mathrm{Fr}_{t}$ is the ratio of inertial forcing to buoyant forcing in the energy-bearing scales of turbulence and can be estimated as

$$
\mathrm{Fr}_{t}=\left(\frac{l_{o}}{l_{e}}\right)^{2 / 3}
$$

Values of the Ellison length scale calculated from the density data were fairly noisy and so could not be used. Instead, we assume a constant relationship between the Ellison and Prandtl mixing-length scales, $l_{e} \approx c l_{m}$, that follows from a scaling argument outlined in Shih et al. (2005) and is consistent with their results from direct numerical simulations (DNS) of sheared stratified turbulence that span a large range of Richardson numbers (0.04-0.6), where they found $c=2.5$ for turbulence in the energetic regime $\left(\varepsilon / \nu N^{2}>100\right)$.

Ivey and Imberger (1991) divide the $\mathrm{Re}_{t}-\mathrm{Fr}_{t}$ diagram (Fig. 9) into three regions: in region 1 turbulence is affected by buoyancy (see Itsweire et al. 1993) but may be isotropic at the smallest scales; region 2 represents the buoyancy-controlled domain; and in region 3 turbulence is extinguished due to the combined effects of buoyancy and friction and only internal-wave motions remain (Gibson 1980; Luketina and Imberger 1989). The flows observed in this study span a wide range of turbulent Reynolds numbers but are generally very energetic $\left(\operatorname{Re}_{t} \sim\right.$ $10^{2}$ to $10^{6}$ ). Here, $\mathrm{Fr}_{t}$ ranges from $10^{-2}$ to $10^{1}$, placing the data in regions 1 and 2 . Figure 9 illustrates the highly variable nature of $R_{f}$ measured in the stratified TBBL over Conch Reef. Contrary to what might be expected, the highest values of $R_{f}$ were not measured in a cluster around $\mathrm{Fr}_{t} \sim 1$ but rather when $\mathrm{Fr}_{t}<1$. This result differs from the idea that the most efficient turbulent mixing occurs when the characteristic scale of stratification is approximately equal to the size of the energetic overturning eddies but rather suggests that efficient mixing can also occur within region 2 , the buoyancy-dominated regime. In this region of the diagram, $l_{e}>l_{0}$, which cannot hold for isotropic turbulence in equilibrium, because the largest scales of turbulence would be damped by buoyant forces. However, observations of the characteristic scale of energetic turbulent eddies exceeding the Ozmidov scale are not uncommon in our measurements and seem to occur frequently during periods of internal-wave forcing on the reef (see examples in Fig. 6h). One explanation for this finding is that the turbulence measured during these periods is not in local equilibrium but rather includes nonlocal effects such as the horizontal advection of turbulent energy by internalwave-driven flows.

The parameter $\mathrm{Re}_{b}$ has been used extensively in the parameterization of stratified turbulence and is derived from the ratio of the Ozmidov scale to the Kolmogorov scale,

$$
\operatorname{Re}_{b}=\left(\frac{l_{0}}{l_{k}}\right)^{4 / 3}=\frac{\varepsilon}{\nu N^{2}}
$$

thus, it represents the range of energetic turbulent scales in a stratified environment when $l_{0}$ is limiting the size of turbulent eddies (as in region 2 of Fig. 9). The relationship between $R_{f}$ and $\mathrm{Re}_{b}$ for ensembles where $l_{0} \leq l_{m}$ is shown in Fig. 10a, where ensembles have been sorted according to $\mathrm{Re}_{b}$ and bin averaged into groups of 6 points. Similarly, $R_{f}$ is shown as a function of $\mathrm{Ri}_{g}$, for all ensembles (regions 1 and 2 of Fig. 9), sorted by $\mathrm{Ri}_{g}$ and then bin averaged into groups of 30 data points (Fig. 10b).

In DNS of sheared stratified turbulence, Shih et al. (2005) found a power-law-type relationship between mixing efficiency and turbulence intensity (also called $\left.\operatorname{Re}_{b}\right)$ in the energetic regime $\left(\varepsilon / \nu N^{2}>100\right)$ of the form

$$
R_{f} \sim 1.5\left(\varepsilon / \nu N^{2}\right)^{-1 / 2} .
$$

Our observations of $R_{f}$ in the Conch Reef TBBL also suggest a power-law-type dependence on $\operatorname{Re}_{b}$ (Fig. 10a); however, we find higher mixing efficiencies than have been found in DNS or laboratory studies. Our observations suggest that $\varepsilon / \nu N^{2}$ may be useful in predicting mixing efficiency in regions of buoyancy-controlled turbulence. However, it is not intuitive why $R_{f}$ should depend on molecular viscosity, and it is possible that another parameter, of the same dimensions (length ${ }^{2} /$ time ), 

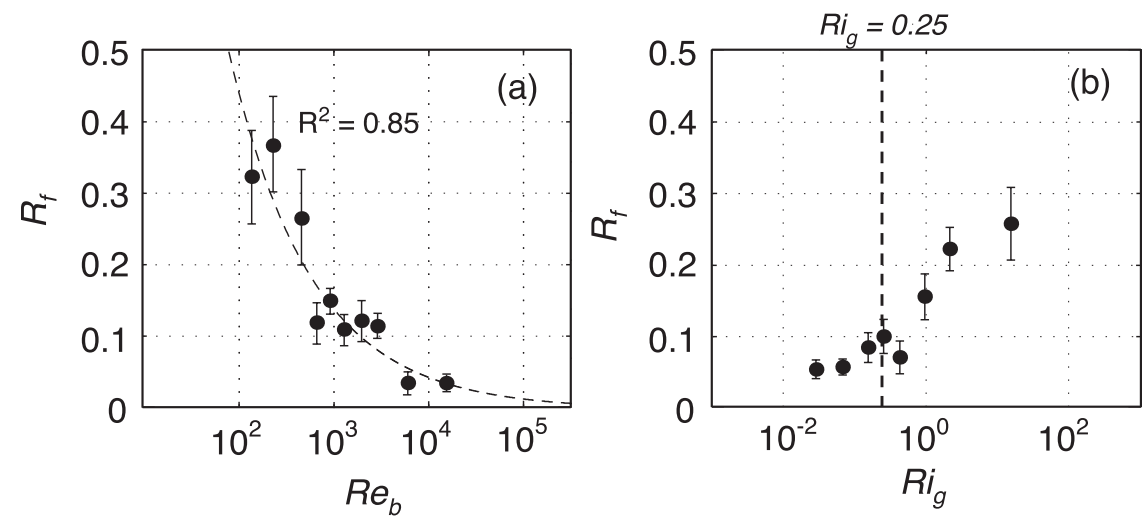

FIG. 10. Flux Richardson number $R_{f}$ as a function of (a) the buoyancy Reynolds number, where the dashed line is the least squares power-law fit of the form $R_{f} \sim 4.5\left(\varepsilon / \nu N^{2}\right)^{-0.5}$ and (b) the gradient Richardson number.

may be more appropriate. The term $\mathrm{Re}_{b}$ can also be written in terms of other dimensionless parameters,

$$
\varepsilon / \nu N^{2} \sim \mathrm{Re}_{t} / \mathrm{Ri}_{g} \sim \mathrm{Re}_{t} \mathrm{Fr}_{t}^{2} .
$$

It is possible that mixing efficiency in a buoyancycontrolled turbulent environment is better described by a Reynolds-Richardson number or Reynolds-Froude number aggregate than by $\mathrm{Re}_{t}, \mathrm{Fr}_{t}$, or $\mathrm{Ri}_{g}$ alone (Shih et al. 2005).

Figure 10b shows a clear dependence of $R_{f}$ on $\mathrm{Ri}_{g}$, with $R_{f}$ increasing with increasing $\mathrm{Ri}_{g}$ for $\mathrm{Ri}_{g}<1$ and $R_{f}$ constant for $\mathrm{Ri}_{g}>1$. Note that nonzero $R_{f}$ only implies efficient mixing and not necessarily high rates of mixing. As seen in the data synthesis given by Zilitinkevich et al. (2008), the presence of turbulence and turbulent mixing at large $\mathrm{Ri}_{g}$ has been observed previously, although not always (e.g., Pardyjak et al. 2002). Indeed, Zilitinkevich et al. (2008) find that $R_{f}$ at large $\mathrm{Ri}_{g}$, whereas our data appear to asymptote to 0.25 . Nonetheless, DNS computations of homogeneous stratified-shear flows (e.g., Holt 1990) do not show this behavior; instead, turbulence collapses when $\mathrm{Ri}_{g}>0.25$. Thus, as suggested by Zilitinkevich et al. (2008), turbulent mixing in strongly stratified conditions such as we observed must be due to transport of energy from a region of high TKE, in our case the very rough reef boundary, to the region of strong stratification above (i.e., these strongly stratified flows are not in local equilibrium).

\section{Conclusions}

Turbulence in the bottom boundary layer over Conch Reef is highly variable in time and is modified by nearbed flow, shear, and stratification driven by shoaling internal waves. In the absence of internal-wave activity on the outer shelf, the near-bed region is relatively well mixed and flow is typically oriented alongshelf. In the alongshelf flow regime, currents from 1 to 5 mab are well described by a logarithmic velocity profile (Fig. 4a). However, the near-bed velocity profile (Fig. 4c) displays a departure from the logarithmic shape in the bottommost meter of the water column, and profiles of Reynolds stresses (Fig. 4d) peak at ADV 2.

We present evidence that internal waves shoaling on the shelf can induce significant increases in stratification, flow speed, shear, and $\varepsilon$ in the TBBL (Figs. 6, 7). Direct estimates of $R_{f}$ confirm previous laboratory, numerical, and observational work, which find mixing efficiency not to be a constant but rather to vary with the $\mathrm{Fr}_{t}, \mathrm{Re}_{b}$, and $\mathrm{Ri}_{g}$. Our measurements of $R_{f}$ do, however, depart from previous observations in that the highest levels of mixing efficiency occur for $\mathrm{Fr}_{t}<1$, suggesting that efficient mixing can also happen in regions of buoyancy-controlled turbulence (Figs. 9, 10).

Measuring turbulence in natural environments is often difficult. However, estimating momentum and buoyancy fluxes in an environment characterized by a range of physical roughness (reef formations), unsteady forcing, and stratification (from breaking internal waves) in the presence of surface waves is particularly challenging. We present factors that can contribute to uncertainty and potential bias in these measurements in section 4 and the appendix. Of these factors, the most concerning is the possible contamination of our turbulence measurements by surface waves, which we have tried to account for, and by nonlinear internal waves, which cannot be separated from the turbulence measurements. Furthermore, we have not accounted for possible waveturbulence interactions in our calculations. We note that the balance (or imbalance) of production and dissipation we observed appears to be independent of the 
strength of wave forcing. Moreover, current models of wave-current interaction that neglect wave effects on turbulence above the wave boundary layer (e.g., Grant and Madsen 1979) appear to successfully describe the structure of the turbulent boundary layer. Nonetheless, arguably the effect of wave-turbulence interactions on mixing in the bottom boundary layer remains an open question.

Results from this study suggest that, for reef communities exposed to continental slope and shelf processes, internal waves may play an important role in flow-dependent ecological processes through the modification of TBBL flow conditions. Additionally, it may be important to include the effects of internal waves to accurately parameterize turbulence in hydrodynamic and biogeochemical models that are being used to make predictions about the severity of rising threats to coral reefs such as high SSTs and ocean acidification.

Acknowledgments. Field support and ship time for this study were generously provided by the National Undersea Research Center in Key Largo, Florida. We thank Greg Shellenbarger, James Hench, Matthew Reidenbach, Mike Murray, and Amatzia Genin for diving assistance; many members of the Stanford EFML for providing field support; and Patrick Wyse at PrimeTest, Inc. for technical assistance. We acknowledge valuable discussions with Jeff Koseff, Jim Moum, Falk Feddersen, John Trowbridge, Rocky Geyer, Anthony Kirincich, and Emily Shroyer, and the tremendous effort by three anonymous reviewers. Funding was provided by grants from the National Oceanic and Atmospheric Administration's National Undersea Research Program, National Science Foundation Grants OCE-0622967 and OCE- 0824972 to SGM, and the Singapore Stanford Program. Kristen Davis was supported by a National Defense Science and Engineering Graduate Fellowship and an ARCS Foundation Fellowship.

\section{APPENDIX}

\section{Calculation of Turbulence Parameters and Uncertainty}

This appendix details procedures for estimating turbulent dissipation, momentum fluxes, and density fluxes, including turbulence-wave decomposition strategies and estimates of uncertainty.

\section{a. Turbulent dissipation}

TKE dissipation $\varepsilon$ was estimated for each ensemble by fitting the high-frequency portion of the observed two-sided vertical velocity spectrum (above the wave peak) to a model of the one-dimensional wavenumber spectrum of velocity fluctuations,

$$
S_{\eta \eta}(k)=\frac{9}{55} \frac{\left(4-\cos ^{2} \theta\right)}{3} \alpha \varepsilon^{2 / 3} k^{-5 / 3},
$$

where $\theta$ represents the angle between the velocity fluctuations and the direction of mean flow $(\theta=\pi / 2$ for the transverse component of flow), $\alpha=1.5$ is the empirically derived Kolmogorov constant, and $k$ represents wavenumber (Shaw et al. 2001). Each 10-min segment was detrended, a Hamming window was applied, and power spectra were averaged over 64 segments of equal length with $50 \%$ overlap, resulting in 166 degrees of freedom (dof). The noise floor, calculated as the average of the power spectrum above $10 \mathrm{~Hz}$ in each ensemble, was subtracted from the power spectral density.

To accurately estimate $\varepsilon$ from the a single velocity component, the turbulence must be locally isotropic (Gargett et al.1984), a reasonable assumption given that our measurements fall within the energetic turbulent regime $\left(\varepsilon / \nu N^{2}>10^{2}\right.$; see Fig. 9), and the inertial subrange region of the spectrum must exist, indicating adequate separation between production and dissipation. Example power spectra for $u, w$, and $\rho$ are shown for all instrument heights and for three Richardson number regimes: subcritical, $\mathrm{Ri}_{g}<0.25$; critical, $0.25<\mathrm{Ri}_{g}<1$; and strongly stratified, $\mathrm{Ri}_{g}>1$ (Figs. A1-A3). Example spectra in all Richardson number regimes exhibit a broad inertial subrange, ranging 1-2 decades in width, with a peak in spectral power at the central surface-wave frequency, corresponding to a wave period of approximately $5.5 \mathrm{~s}$. For the entire dataset, it was found that the inertial subrange spanned at least a decade when $u_{*}>$ $0.2 \mathrm{~cm} \mathrm{~s}^{-1}$ and the turbulence Reynolds number $R_{L}$ was greater than 1500 . These two constraints were used to identify ensembles where $\varepsilon$ could be adequately estimated using the spectral fitting technique. To account for the effect of surface waves, we employed the Lumley and Terray (1983) model for the effect of a random wave field on the turbulent spectrum and followed the method outlined in the appendix of Feddersen et al. (2007). Additionally, to limit the effect of unsteady advection of turbulence by waves, we restricted the dissipation estimates (as well as momentum and density flux estimates) to ensembles where $\beta<1$ to ensure that wave orbital velocities did not exceed the mean current. Uncertainty in $\varepsilon$ is dependent on the "goodness of fit" of the inertial subrange to the model spectrum (Gross and Nowell 1985). Error in this fit was propagated to the estimate of dissipation, resulting in an average error of $\pm 27 \% \varepsilon$ for each estimate. 

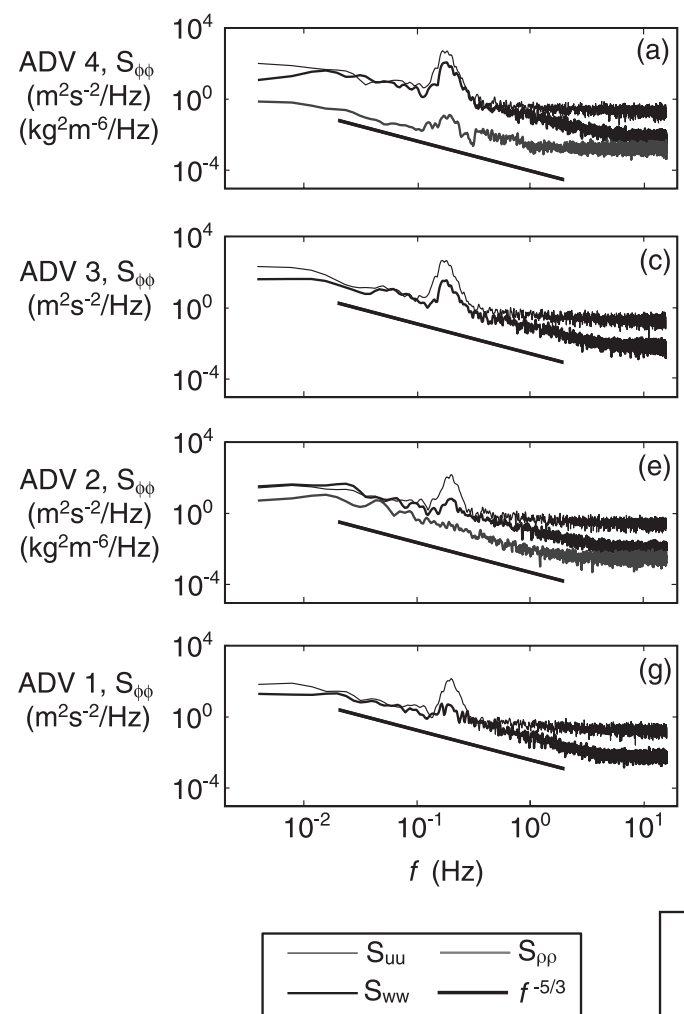
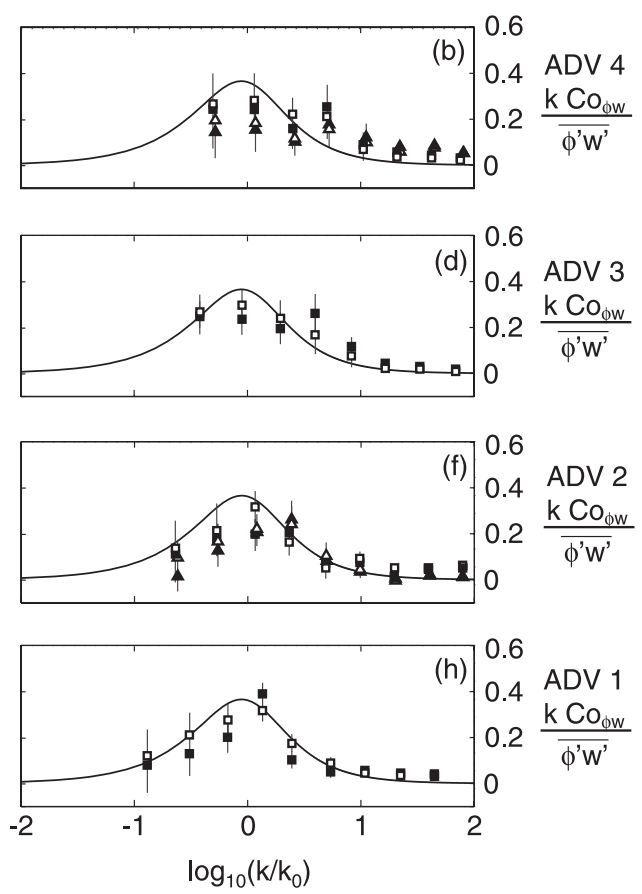

$$
\begin{aligned}
& \text { - } \mathrm{k} \mathrm{Co}_{\mathrm{uw}} / \overline{\mathrm{u}^{\prime w^{\prime}}} \text { (raw) } \\
& \text { - } \mathrm{k} \mathrm{Co}_{\rho \mathrm{w}} / \overline{\rho^{\prime} \mathrm{w}^{\prime}}(\mathrm{raw}) \\
& \text { Kaimal et al. (1972) }
\end{aligned}
$$

FIG. A1. (left) Spectra and cospectra for the case of subcritical gradient Richardson number $\left(\operatorname{Ri}_{g}<0.25\right)$. Example velocity spectra and density spectra for (a) ADV 4, (c) ADV 3, (e) ADV 2, and (g) ADV 1, for an ensemble at 1350 LT 18 Jul 2005, where $\beta=0.9$ at ADV 4. (right) Observed cospectra compared to the Kaimal et al. (1972) model. The variance-preserving cospectra were normalized by the covariance estimate and grouped into bins by wavenumber then averaged over all ensembles where $\mathrm{Ri}_{g}<0.25$ and $\beta<1$ (721 ensembles), for (b) ADV4, (d) ADV 3, (f) ADV 2, and (h) ADV 1 as a function of normalized wavenumber. The median value for each bin is shown as a circle, and vertical error bars show two standard errors on the distributions.

\section{b. Momentum and density fluxes}

To remove wave contamination from the momentum and density flux estimates, we employed a method originally developed by Trowbridge (1998), modified by Shaw and Trowbridge (2001), and further improved by Feddersen and Williams (2007, hereafter FW07), which uses the velocity signals between two adjacent sensors spaced at a distance such that the wave-induced velocities are coherent, whereas turbulent fluctuations are uncorrelated. The FW07 method applies an adaptive filtering technique to account for wave velocity magnitude and phase shifts between sensors in both horizontal and vertical velocities. After the filtering is applied, the wave-induced velocities are assumed to be equal in each signal and can be cancelled by differencing, leaving only the turbulent component of the velocity. Momentum $\left(\overline{u^{\prime} w^{\prime}}\right.$ and $\left.\overline{v^{\prime} w^{\prime}}\right)$ and density fluxes $\left(\overline{\rho^{\prime} w^{\prime}}\right)$ were then calculated as the direct covariance of the turbulent component of the velocity and density signals and then averaged over each 10-min ensemble. The pairing of ADVs for implementation of the FW07 method is detailed in Table A1. The ratio of vertical separation of instruments to the height above the bed $\Delta z / z$ ranges from 1 to 4 and is in all cases less than the recommended value by Shaw and Trowbridge (2001), $\Delta z / z>5$. To ensure that turbulence was uncorrelated between the paired sensors, we required that the covariance of velocity components at the same instrument was at least an order of magnitude larger than the covariance between paired instruments (i.e., $\overline{u_{(1)}^{\prime} w_{(1)}^{\prime}} \gg \overline{u_{(1)}^{\prime} w_{(2)}^{\prime}}$ ).

To address the quality of the momentum and density flux estimates in the presence of surface-wave forcing and stratification, we compared the momentum and buoyancy cospectra before and after FW07 wave filtering to the Kaimal et al. (1972) semiempirical form of the cospectrum. Figures A1-A3 show the observed variancepreserving cospectra normalized by the covariance estimate of the flux, then averaged over all ensembles where $\beta<1$, for the three Richardson number regimes defined 

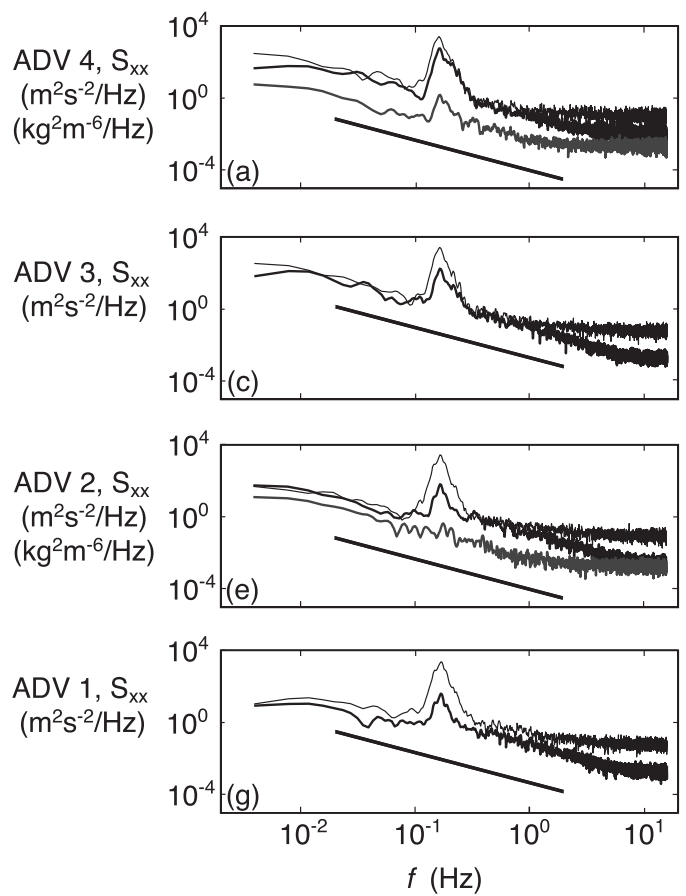
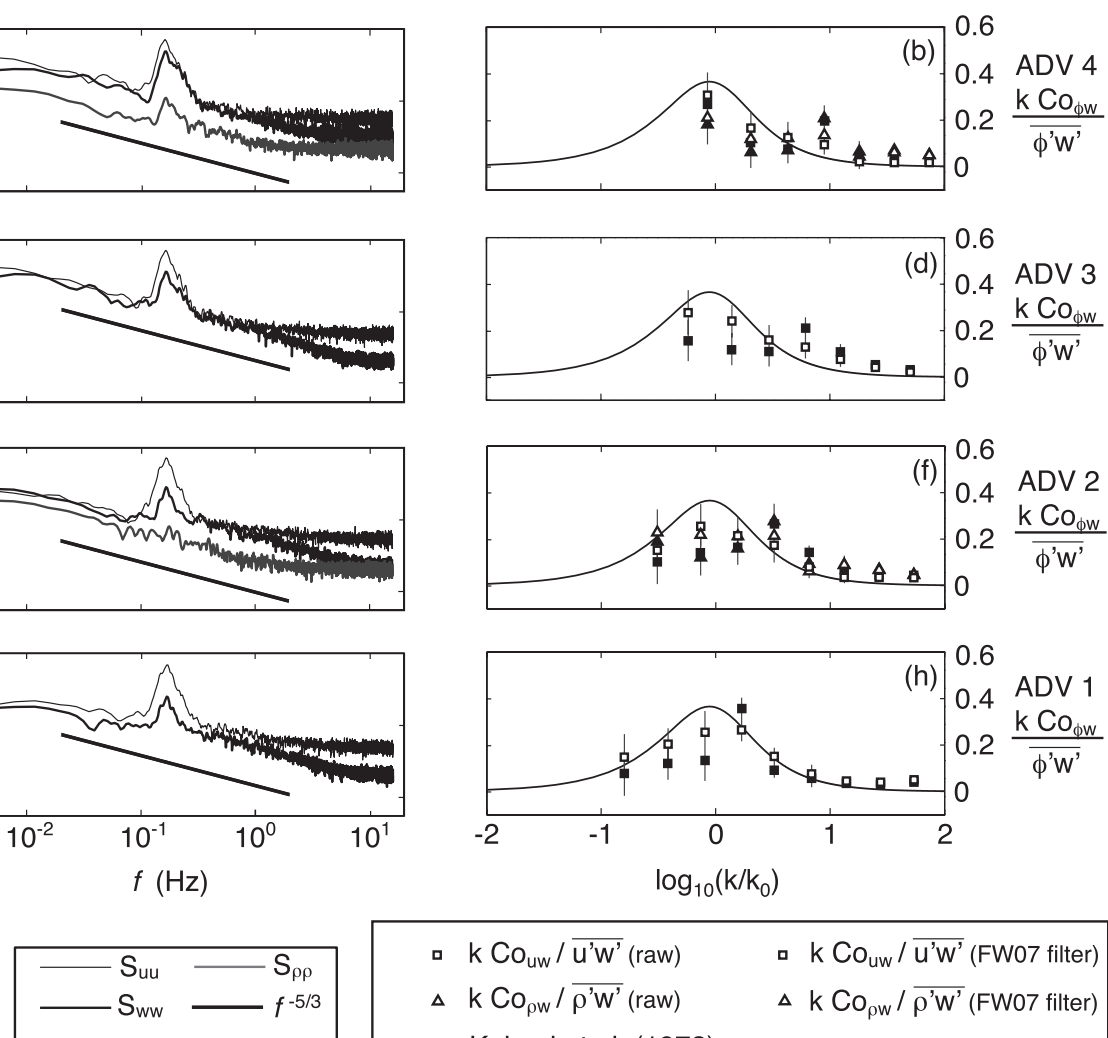

FIG. A2. As in Fig. A1, but for a critical gradient Richardson number $\left(0.25<\mathrm{Ri}_{g}<1\right)$ at $1355 \mathrm{LT} 17 \mathrm{Jul}$ 2005. (right) Averaged over all ensembles where $0.25<\mathrm{Ri}_{g}<1$ and $\beta<1$ (264 ensembles).

above and plotted against the wavenumber $k$, normalized by the "rolloff" wavenumber, $k_{0} \sim 2 \pi / l_{m}$. The raw cospectra for all instruments and all $\mathrm{Ri}_{g}$ regimes exhibit a peak in energy at normalized wavenumbers corresponding to surface gravity waves. The FW07-filtered cospectra fall closer to the Kaimal et al. (1972) model spectrum. To ensure that our flux estimates are reasonable, we imposed a constraint that the correlation between the wave-filtered cospectra and the Kaimal et al. (1972) curve was greater than 0.7.

Uncertainty in the Reynolds stress estimates is rather large because of the presence of intermittent events in the data. The autocorrelation time scale for the velocity covariance was approximately $3 \mathrm{~s}$, resulting in $200 \mathrm{dof}$ per ensemble and a $90 \%$ confidence interval of approximately $\pm 35 \% \overline{u^{\prime} w^{\prime}}$. The autocorrelation time scale for the density flux was approximately $2 \mathrm{~s}$, giving 300 dof per ensemble and a $90 \%$ confidence interval of $\pm 57 \% \overline{\rho^{\prime} w^{\prime}}$. Although the FW07 technique adequately removed the effects of surface waves in the momentum and density flux estimates for most ensembles, it is not entirely apparent how much the internal-wave bias affects the flux values observed. Differencing wave-removal techniques do not eliminate internal-wave bias because the near-bottom structure of internal waves is highly nonlinear (Shaw and Trowbridge 2001). Turbulent production is calculated as the product of ensemble-averaged shear and momentum flux, which were found generally to be aligned in the same direction (within $10^{\circ}$ ).

\section{c. Uncertainty in estimates of density and parameters derived from density}

The uncertainty in $\rho$ and all parameters derived from $\rho\left(N, \mathrm{Ri}_{g}\right.$, and $\left.\mathrm{Re}_{b}\right)$ are subject to error from two sources: instrument accuracy and the calculation of density using an empirical relationship between temperature and salinity. Three instruments are used to measure temperature on the reef in this study (manufacturer's specified accuracy in parentheses): Seabird SBE-39 temperature loggers $\left( \pm 0.002^{\circ} \mathrm{C}\right)$, Nortek vectors $\left( \pm 0.1^{\circ} \mathrm{C}\right)$, and PME fast-response FP07 temperature sensors $\left( \pm 0.01^{\circ} \mathrm{C}\right)$. Density on the reef was estimated from third-order polynomial fit between temperature and salinity established from three CTDs located approximately $500 \mathrm{~m}$ offshore. CTD measurements showed that density varied primarily with temperature and the root-mean-square error for density calculated from the derived relationship was found to be $0.036 \mathrm{~kg} \mathrm{~m}^{-3}$. Random error associated 

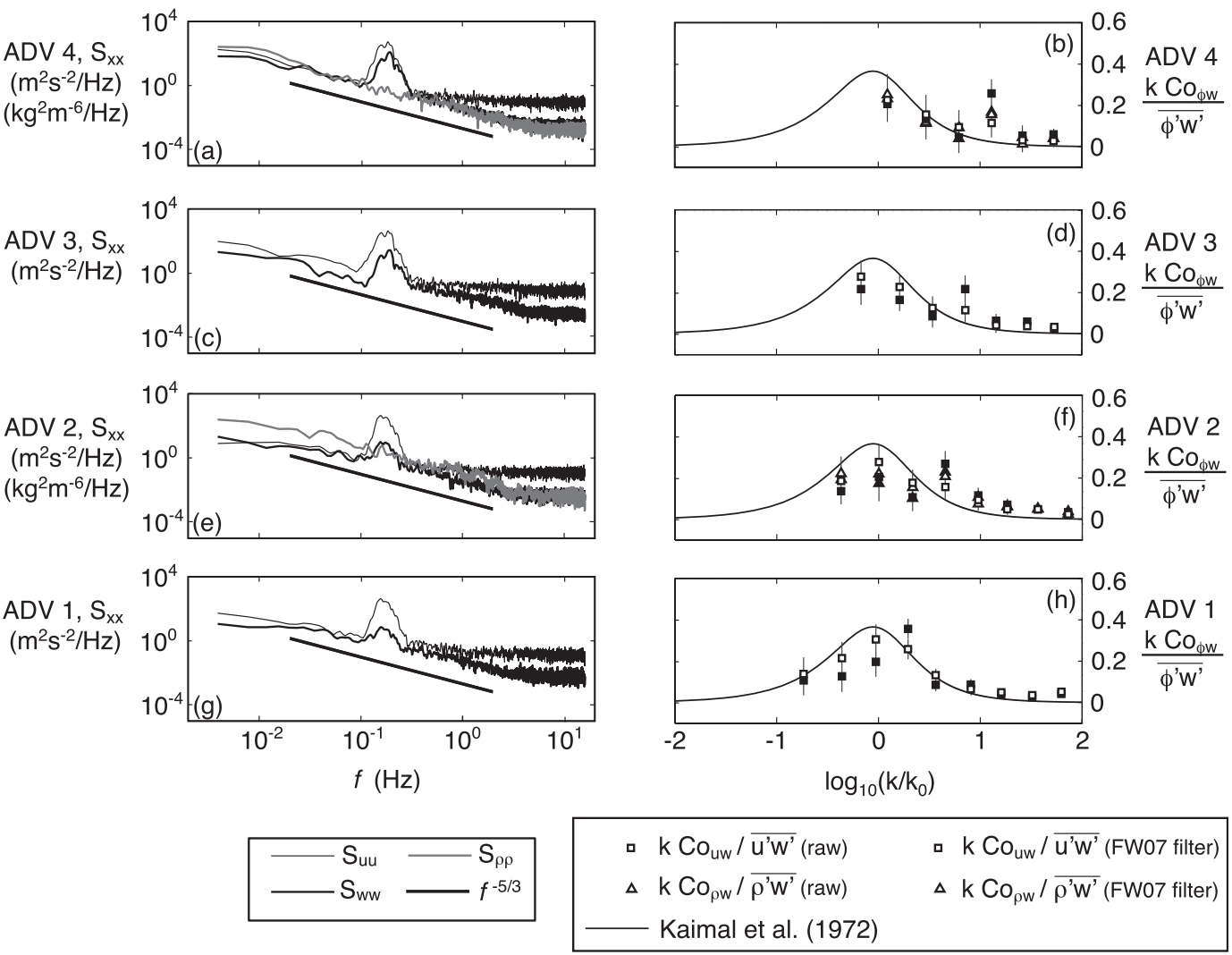

FIG. A3. As in Fig. A1, but for the case of strong stratification $\left(\mathrm{Ri}_{g}>1\right)$ at $2325 \mathrm{LT} 16 \mathrm{Jul} 2005$. (right) Averaged over all ensembles where $\mathrm{Ri}_{g}>1$ and $\beta<1$ ( 252 ensembles).

with this estimation, when averaged over a 10 -min ensemble, reduces to $\sigma_{\rho, 10-\min }= \pm 0.002 \mathrm{~kg} \mathrm{~m}^{-3}$, propagating to $N, \sigma_{\mathrm{N}, 10-\min }= \pm 0.002 \mathrm{~Hz}$. To estimate $N$ between ADV temperature sensors, we must also consider the bias error in these sensors. The bias error was estimated by comparing the ADV temperature sensors to the more accurate FP07s during a "calibration" period when the water column was well mixed (temperatures over the entire water column were within $0.01^{\circ} \mathrm{C}$ according to nearby SBE-39 and FP07 sensors). The average bias was found to be $0.08^{\circ} \mathrm{C}$. The ADV temperature sensor is stable, so we used the bias calculated during the calibration period for each instrument to correct the ADV temperature measurements over the entire time series,

TABLE A1. ADV instrument pairings: Velocities from instrument in first column are filtered with velocities from instrument in second column.

\begin{tabular}{lcc}
\hline \hline ADV (mab) & Paired with ADV (mab) & $\Delta z / z$ \\
\hline ADV 1 (0.25) & ADV 2 (0.6) & 1.4 \\
ADV 2 (0.6) & ADV 4 (3.0) & 4.0 \\
ADV 3 (1.5) & ADV 4 (3.0) & 1.0 \\
ADV 4 (3.0) & ADV 3 (1.5) & 2.0 \\
\hline
\end{tabular}

reducing the bias to within the accuracy of the FP07 $\left( \pm 0.01^{\circ} \mathrm{C}\right)$. Propagating the bias error to quantities derived from the ADV temperature measurements results in the following uncertainties: $N= \pm 0.006 \mathrm{~Hz} ; \mathrm{Ri}_{g}=$ $\pm 1.2 \times 10^{-4} ; l_{o}= \pm 0.001 \mathrm{~m} ; \mathrm{Fr}_{t}= \pm 0.01 ;$ and $\operatorname{Re}_{b}=$ $\pm 1.2 \times 10^{-4}$.

\section{REFERENCES}

Barrett, T. K., and C. W. V. Atta, 1991: Experiments on the inhibition of mixing in stably stratified decaying turbulence using laser Doppler anemometry and laser-induced fluorescence. Phys. Fluids, A3, 1321-1332.

Barry, M. E., G. N. Ivey, K. B. Winters, and J. Imberger, 2001: Measurements of diapycnal diffusivities in stratified fluids. J. Fluid Mech., 442, 267-291.

Bendat, J. S., and A. G. Piersol, 2000: Random Data Analysis and Measurement Procedures. Wiley, 594 pp.

Chriss, T. M., and D. R. Caldwell, 1982: Evidence for the influence of form drag on bottom boundary layer flow. J. Geophys. Res., 87, 4148-4154.

Davis, K. A., J. J. Leichter, J. L. Hench, and S. G. Monismith, 2008: Effects of western boundary current dynamics on the internal wave field of the southeast Florida shelf. J. Geophys. Res., 113, C09010, doi:10.1029/2007JC004699.

Doron, P., L. Bertuccioli, and J. Katz, 2001: Turbulence characteristics and dissipation estimates in the coastal ocean bottom 
boundary layer from PIV data. J. Phys. Oceanogr., 31, 21082134.

Etemad-Shahidi, A., and J. Imberger, 2001: Anatomy of turbulence in thermally stratified lakes. Limnol. Oceanogr., 46, 11581170.

Feddersen, F., and A. J. Williams, 2007: Direct estimation of the Reynolds stress vertical structure in the nearshore. J. Atmos. Oceanic Technol., 24, 102-116.

— J. H. Trowbridge, and A. J. Williams, 2007: Vertical structure of dissipation in the nearshore. J. Phys. Oceanogr., 37, 17641777.

Finnigan, J., 2000: Turbulence in plant canopies. Annu. Rev. Fluid Mech., 32, 519-571.

Gargett, A. E., T. R. Osborn, and P. W. Nasmyth, 1984: Local isotropy and the decay of turbulence in a stratified fluid. J. Fluid Mech., 144, 231-280.

Gibson, C. H., 1980: Fossil temperature, salinity, and vorticity turbulence in the ocean. Marine Turbulence, Elsevier, 221-257.

Grant, W. D., and O. S. Madsen, 1979: Combined wave and current interaction with a rough bottom. J. Geophys. Res., 84, 17971808.

— and - 1986: The continental-shelf bottom boundary layer. Annu. Rev. Fluid Mech., 18, 265-305.

Gross, T. F., 1999: Momentum and energy transfer in the oceanic law of the wall region. J. Atmos. Oceanic Technol., 16, 16681672.

_ in a tidal boundary layer. Cont. Shelf Res., 2, 109-126.

- , and -1985 : Spectral scaling in a tidal boundary layer. J. Phys. Oceanogr., 15, 496-507.

Holt, S. E., 1990: The evolution and structure of homogenous stably stratified sheared turbulence. Ph.D. thesis, Stanford University, Department of Civil and Environmental Engineering, $184 \mathrm{pp}$.

Itsweire, E. C., J. R. Koseff, D. A. Briggs, and J. H. Ferziger, 1993: Turbulence in stratified shear flows: Implications for interpreting shear-induced mixing in the ocean. J. Phys. Oceanogr., 23, 1508-1522.

Ivey, G. N., and J. Imberger, 1991: On the nature of turbulence in a stratified fluid. Part I: The energetics of mixing. J. Phys. Oceanogr., 21, 650-658.

— , K. B. Winters, and J. R. Koseff, 2008: Turbulence, but how much mixing? Annu. Rev. Fluid Mech., 40, 169-184.

Kaimal, J. C., J. C. Wyngaard, Y. Izumi, and O. R. Cote, 1972: Spectral characteristics of surface layer turbulence. Quart. J. Roy. Meteor. Soc., 98, 563-589.

Kielmann, J., and W. Duing, 1974: Tidal and sub-inertial fluctuations in the Florida Current. J. Phys. Oceanogr., 4, 227-236.

Lee, T. N., 1975: Florida Current spin-off eddies. Deep-Sea Res., 22, 753-765.

-1986: Coastal circulation in the Key Largo Coral Reef Marine Sanctuary. Physics of Shallow Estuaries and Bays, J. V. D. Kreeke, Ed., Springer, 178-198.

Leichter, J. J., S. R. Wing, S. L. Miller, and M. W. Denny, 1996: Pulsed delivery of subthermocline water to Conch Reef (Florida Keys) by internal tidal bores. Limnol. Oceanogr., 41, 1490-1501.

—_, G. Shellenbarger, S. J. Genovese, and S. R. Wing, 1998: Breaking internal waves on a Florida (USA) coral reef: A plankton pump at work? Mar. Ecol. Prog. Ser., 166, 83-97.

- , H. L. Stewart, and S. L. Miller, 2003: Episodic nutrient transport to Florida coral reefs. Limnol. Oceanogr., 48, 13941407.
_ , G. B. Deane, and M. D. Stokes, 2005: Spatial and temporal variability of internal wave forcing on a coral reef. J. Phys. Oceanogr., 35, 1945-1962.

Lorke, A., F. Peeters, and A. Wüest, 2005: Shear-induced convective mixing in bottom boundary layers on slopes. Limnol. Oceanogr., 50, 1612-1619.

—, L. Umlauf, and V. Mohrholz, 2008: Stratification and mixing on sloping boundaries. Geophys. Res. Lett., 35, L14610, doi:10.1029/2008GL034607.

Lueck, R. G., F. Wolk, and H. Yamazaki, 2002: Oceanic velocity microstructure measurements in the 20th century. J. Oceanogr., 58, 153-174.

Luketina, D. A., and J. Imberger, 1989: Turbulence and entrainment in a buoyant surface plume. J. Geophys. Res., 94,12 619-12 636

Lumley, J. L., and E. A. Terray, 1983: Kinematic of turbulence convected by a random wave field. J. Phys. Oceanogr., 13, 2000-2007.

McCormick, M. I., 1994: Comparison of field methods for measuring surface topography and their associations with a tropical reef fish assemblage. Mar. Ecol. Prog. Ser., 112, 87-96.

Mellor, G., 2002: Oscillatory bottom boundary layers. J. Phys. Oceanogr., 32, 3075-3088.

Miles, J. W., 1961: On the stability of heterogeneous shear flows. J. Fluid Mech., 10, 496-508.

Moum, J. N., 1996: Efficiency of mixing in the main thermocline. J. Geophys. Res., 101, 12 057-12 069.

— , and T. P. Rippeth, 2008: Do observations adequately resolve the natural variability of oceanic turbulence? J. Mar. Syst., 77, 409-417.

Munk, W., and C. Wunsch, 1998: Abyssal recipes II: Energetics of tidal and wind mixing. Deep-Sea Res. I, 45, 1977-2010.

Osborn, T. R., 1980: Estimates of the local rate of vertical diffusion from dissipation measurements. J. Phys. Oceanogr., 10, 83-89.

Pardyjak, E. R., P. Monti, and H. J. S. Fernando, 2002: Flux Richardson number measurements in stable atmospheric shear flows. J. Fluid Mech., 459, 307-316.

Parr, A. E., 1937: Report on hydrographic observations at a series of anchor stations across the Straits of Florida. Bull. Bingham Oceanogr. Coll., 6, 1-63.

Perlin, A., J. N. Moum, and J. M. Klymak, 2005a: Response of the bottom boundary layer over a sloping shelf to variations in alongshore wind. J. Geophys. Res., 110, C10S09, doi:10.1029/ 2004JC002500.

,,,--- M. D. Levine, T. Boyd, and P. M. Kosro, 2005b: A modified law-of-the-wall applied to oceanic bottom boundary layers. J. Geophys. Res., 110, C10S10, doi:10.1029/2004JC002310.

Prandtl, L., 1925: Bericht uber die Entstehung der Turbulenz. Z. Angew. Math. Mech., 5, 136-139.

Rehmann, C. R., and J. R. Koseff, 2004: Mean potential energy change in stratified grid turbulence. Dyn. Atmos. Oceans, 37, 271-294.

Reidenbach, M. A., S. G. Monismith, J. R. Koseff, G. Yahel, and A. Genin, 2006: Boundary layer turbulence and flow structure over a fringing coral reef. Limnol. Oceanogr., 51, 1956-1958.

Reynolds, W. C., and A. K. M. F. Hussain, 1972: The mechanics of an organized wave in turbulent shear flow. Part 3. Theoretical models and comparisons with experiments. J. Fluid Mech., 54, 263-288.

Rohr, J. J., E. C. Itsweire, K. N. Helland, and C. W. V. Atta, 1988: An investigation of the growth of turbulence in a uniformmean-shear flow. J. Fluid Mech., 187, 1-33.

Sanford, T. B., and R.-C. Lien, 1999: Turbulent properties in a homogenous tidal bottom boundary layer. J. Geophys. Res., 104, 1245-1257. 
Schmitz, W. J., Jr., and W. S. Richardson, 1968: On the transport of the Florida current. Deep-Sea Res., 15, 679-693.

Shaw, W. J., and J. H. Trowbridge, 2001: The direct estimation of near-bottom turbulent fluxes in the presence of energetic wave motions. J. Atmos. Oceanic Technol., 18, 1540-1557.

- — - and A. J. Williams, 2001: Budgets of turbulent kinetic energy and scalar variance in the continental shelf bottom boundary layer. J. Geophys. Res., 106, 9551-9564.

Shih, L. H., J. R. Koseff, G. N. Ivey, and J. H. Ferziger, 2005: Parameterizations of turbulent fluxes and scales using homogenous sheared stably stratified turbulence simulations. J. Fluid Mech., 525, 193-214.

Smith, W. A. M. N., P. Atsavapranee, J. Katz, and T. R. Osborn, 2002: PIV measurements in the bottom boundary layer of the coastal ocean. Exp. Fluids, 33, 962-971.

Smyth, W. D., J. N. Moum, and D. R. Caldwell, 2001: The efficiency of mixing in turbulent patches: Inferences from direct simulations and microstructure observations. J. Phys. Oceanogr., 31, 19691992

Taylor, J. R., 1993: Turbulence and mixing in the boundary layer generated by shoaling internal waves. Dyn. Atmos. Oceans, 19, 233-258.

Trowbridge, J. H., 1998: Technique for measurement of turbulent shear stress in the presence of surface waves. J. Atmos. Oceanic Technol., 15, 290-298.

, W. R. Geyer, M. M. Bowen, and A. J. Williams III, 1999: Near-bottom turbulence measurements in a partially mixed estuary: Turbulent energy balance, velocity structure, and along-channel momentum balance. J. Phys. Oceanogr., 29, 3056-3072.

Zilitinkevich, S. S., T. Elperrin, N. Kleeorin, I. Rogachevskii, I. Esau, T. Mouritsen, and M. W. Miles, 2008: Turbulence energetics in stably stratified geophysical flows: Strong and weak mixing regimes. Quart. J. Roy. Meteor. Soc., 134, 793-799. 